A

0

0

0

8

0

2

1
5

6

0

Q

159

H9 


\section{HISTORY AND LITERATURE PRIMERS.}

Edited by JOHN RICHARD GREEN.

Author of "A Short History of the English People."

In $18 \mathrm{mo}$, cloth, price $1 s$, each.

Homer. By the Right Hon. W. E. Gladstone.

English Grammar Exercises. By R. MORRIS, LL.D., and H. C. BOWEN.

English Grammar. By R. MOrRIS, LL.D.

History of Rome. By M. Creighton, M.A. With Maps.

History of Greece. By C. A. FyFFE, M.A. With Maps. English Literature. By the Rev. STOPFORD BROOKE, M.A.

History of Europe. By E. A. Freeman, D.C.L., LL.D. With Maps.

Greek Antiquities. By J. P. Mahaffy, M.A. Illustrated.

Roman Antiquities. By Prof. A. S. Wilkins. Illustrated.

Classical Geography. By H. F. TOzER.

Geography. By George Grove, F.R.G.S. With Maps. Children's Treasury of Lyrical Poetry. By F. T. PALGRAVE. In Two Parts. is, each.

Shakspere. By Prof. Dowden.

Philology. By J. Peile, M.A.

Greek Literature. By Prof. JebB, M.A.

France. By Charlotte M. Yonge.

English Composition. By Prof. Nichol.

* *thers in preparation.

MACMILLAN AND CO, LONDON. 

7. Pollock 


\section{S.C. K. OGBEN. Sirerte frimers.}

\section{INTRODUCTORY.}

BY

PROFESSOR HUXLEY, F.R.S.

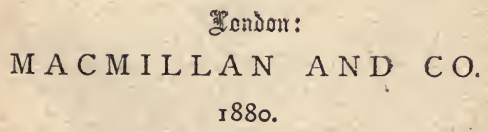

The Right of Translation and Reproduction is Reserved. 


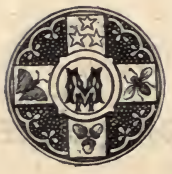


 \\ $\therefore \quad$ LTBRARY}

TABLENIOF CONAENTS

H9

ART. SECT.

NATURE AND SCIENCE.

I.

2.

3.

4.

5.

6.

7.

8.

9.

Io.

II.

12.

23.

I4.

I5.

I6.

I7.

18.

I9.

20.

$2 \mathrm{r}$.

22.

23.

24.

25.

26.

27.

23 .

29.

30.

3 I.

32.

33.

34.

35.

36.

37.

38 ,

39 .

Sensations and Things .

Causes and Effects

The reason Why Explanation

Properties and Powers

Artificial and Natural Objects. Nature : $\quad: \quad 8$

Artificial Things are only Natural Things shaped and brought together or separated by Men

Many Objects and Chains of Causes and Effects in Nature are out of our reach

The Order of Nature: nothing happens by Accident, and there is no such thing as Chance

Laws of Nature: Laws are not Causes: . . ${ }^{\circ}$

Knowledge of Nature is the Guide of Practical C infuct

" Science: the Knowledge of the Laws of Nature obtained by Observation, Experiment, and Reasoning • • • . 16

II. MATERIAL OBJECTS.-(A.) MINERAL BODIES.

, The Natural Object Water . . . .

"A Tumbler of Water $\quad \ldots, \ldots, \ldots, \quad, \quad 20$

"W Water occupies Space ; it offers Resistance; it has Weight; and is able to transfer Motion which it has acquired; it is therefore a form of Matter.

Vivater is a liquid

Water is almost incompressible

The Meaning of Weight.

Gravity and Gravitation.

The cause of Weight: Attriction:

Attraction : Force $\quad 27$

", The Weight of Water is Proportioned to its Bulk. - . 28

"The Measuring of Weights. The Balance . T . 29

"The Weight of the same Bulk or Volume of Water is Constant under the same conditions. Mass. Density .

Equal Volumes of Different Things under the same circumstances, have Different Weights : the Density of Different Bodies is Different

The Meaning of Heavy and Light-Specific Gravity

"The Meaning of Heavy and Light-Specific Gravity ${ }^{\circ}$. Water; Things of less Specific Gravity float

A Body which Floats in Water always occupies as much Space beneath the level of the Surface of the Water as is equal to the Volume of Water which weighs as much as that Body ; in other words, it d splaces its own Weight of Water

Water Presses in all Directions . The Transference of Motion by Moving Water : the Momentum of Moving Water

tum Energy of Moving Water $\quad \vdots \quad \cdots \quad: \quad \vdots \quad \vdots 40$

"The Properties of Water are Constant : . $\quad . \quad 47$

Increase of Heatat first causes Water to Increase in Volume Increase of Heat at length causes Water to become Steam .

The taking away of Heat from Steam causes the Steam to change into Hot Water

When Water is changed into Steam, its Volume becames about $x, 700$ times greater than it was at first

Gases or Elastic Fluids. Air $: 0 .-1$

Steam is an Elastic Fluid or Gas . . . . . f . 54

Gases and Vapours. . . . . . . 55

The Evaporation of Water at ordinary Temperatures . 56

", When .Hot Water is cooled, it Contracts to beg.n with, but after a time Expands . 
ART. SECT.

40. II. Water cooled still further becomes the transparent brittle solid Ice

41. "Ice has less Specific Gravity than the Water from which it was formed

Hoar Frost is the Gaseous Water which exists in the Atmosphere, condensed and converted into Ice Crystals . .

When Ice is warmed it begins to change back into Water as soon as the Temperature reaches $32^{\circ}$.

44.

Ice the solid, Water the liquid, and Steam the gas, are three states of one natural object; the condition of each state being a certain amount of Heat

The Phenomena of Heat are the Effects of a rapid Motion of the Particles of Matter

The Structure of Water.

20

$\ldots$

Suppositions or Hypotheses; their Uses and their Value

The Hypothesis that Water is composed of Separate Parti-

All Matter is probably made up either of Molecules or of

Atoms
Elementary Bodies are neither destroyed nor is their Quantity increased in Nature

\section{Simple Mixture}

$\rightarrow$

Mixture followed by Increase of Density; Alcohol and Water

Solution: Water. Dissolves Salt

Quicklime and Water: Plaster of Paris and Water: Combination

Mineral bodies may take on definite shapes and grow, or increase in size, by the addition of like parts

(B.) LIVING BODIES.

The Wheat Plant and the substances of which it is composed

The common Fowl and the Substances of which it is com-

Certain Constituents of the Body are very similar in the Wheat Plant and in the Fowl

Proteid Substances are met with in Nature only in Animals and Plants; and Animals and Plants always contain Proteids

What is meant by the word Living?

The Living Plant increases in Size, by adding to the Substances which compose its Body, like Substances; these, however, are not derived from without, but are manufactured within the Body of the Plant from simpler Materials

," The Living Plant, after it has grown up, detaches part of its Substance, which has the Power of developing into a similar Plant, as a Seed

The Living Animal increases in Size by adding to the Substances which compose its Body, like Substances; these however are chiefly derived directly from other Animals or from Plants

64 .

The Living Animal, after it has grown up, detaches part of its Substance, which has the Power of growing into a similar Animal, as an Egg .

Living Bodies differ from Mineral Bodies in their Essential Composition, in the manner of their Growth, and in the fact that they are reproduced by Germs 


\section{SCIENCE PRIMERS.}

\section{INTRODUCTORY.}

\section{NATURE AND SCIENCE.}

\section{r. Sensations and Things.}

All the time that we are awake we are learning by means of our senses something about the world in which we live and of which we form a part; we are constantly aware of feeling, or hearing, or smelling, and, unless we happen to be in the dark, of seeing; at intervals we taste. We call the information thus obtained sensation.

When we have any of these sensations we commonly say that we feel, or hear, or smell, or see, or taste, something. A certain scent makes us say we smell onions; a certain flavour, that we taste apples; a certain sound, that we hear a carriage; a certain appearance before our eyes, that we see a tree; and we call that which we thus perceive by the aid of our senses a thing or an object.

\section{Causes and Effects.}

Moreover, we say of all these things, or objects, that they are the causes of the sensations in question, and 
that the sensations are the effects of these causes. For example, if we hear a certain sound, we say it is caused by a carriage going along the road, or that it is the effect, or the consequence, of a carriage passing along. If there is a strong smell of burning, we believe it to be the effect of something on fire, and look about anxiously for the cause of the smell. If we see a tree, we believe that there is a thing, or object, which is the cause of that appearance in our field of view.

\section{The reason Why. Explanation.}

In the case of the smell of burning, when we find on looking about, that something actually is on fire, we say indifferently either that we have found out the cause of the smell, or that we know the reason why we perceive that smell; or that we have explained it. So that to know the reason why of anything, or to explain it, is to know the cause of it. But that which is the cause of one thing is the effect of another. Thus, suppose we find some smouldering straw to be the cause of the smell of burning, we immediately ask what set it on fire, or what is the cause of its burning? Perhaps we find that a lighted lucifer match has been thrown into the straw, and then we say that the lighted match was the cause of the fire. But a lucifer match would not be in that place unless some person had put it there. That is to say, the presence of the lucifer match is an effect produced by somebody as cause. So we ask why did any one put the match there? Was it done carelessly, or did the person who put it there intend to do so? And if so, what was his motive, or the cause which led him to do such a thing? And what was the reason for his having such 
a motive? It is plain that there is no end to the questions, one arising out of the other, that might be asked in this fashion.

Thus we believe : that everything is the effect of something which preceded it as its cause, and that this cause is the effect of something else, and so on, through a chain of causes and effects which goes back as far as we choose to follow it. Anything is said to be explained as soon as we have discovered its cause, or the reason why it exists; the explanation is fuller, if we can find out the cause of that cause; and the further we can trace the chain of causes and effects, the more satisfactory is the explanation. But no explanation of anything can be complete, because human knowledge, at its best, goes but a very little way back towards the beginning of things.

\section{Properties and Powers.}

When a thing is found always to cause a particular effect, we call that effect sometimes a property, sometimes a power of the thing. Thus the odour of onions is said to be a property of onions, because onions always cause that particular sensation of smell to arise, when they are brought near the nose; lead is said to have the property of heaviness, because it always causes us to have the feeling of weight when we handle it; a stream is said to have the power to turn a waterwheel, because it causes the waterwheel to turn; and a venomous snake is said to have the power to kill a man, because its bite may cause a man to die. Properties and powers, then, are certain effects caused by the things which are said to possess them. 


\section{Artificial and Natural Objects. Nature.}

A great many of the things brought to our knowledge by our senses, such as houses and furniture, carriages and machines, are termed artificial things or objects, because they have been shaped by the art of man; indeed, they are generally said to be made by man. But a far greater number of things owe nothing to the hand of man, and would be just what they are if mankind did not exist,- such as the sky and the clouds; the sun, moon and stars; the sea with its rocks and shingly or sandy shores; the hills and dales of the land ; and all wild plants and animals. Things of this kind are termed natural objects, and to the whole of them we give the name of Nature.

\section{Artificial Things are only Natural Things} shaped and brought together or separated by Men.

Although this distinction between nature and art, between natural and artificial things, is very easily made and very convenient, it is needful to remember that, in the long run, we owe everything to nature; that even those artificial objects which we commonly say are made by men, are only natural objects shaped and moved by men; and that, in the sense of creating, that is to say, of causing something to exist which did not exist in some other shape before, man can make nothing whatever. Moreover, we must recollect that what men do in the way of shaping and bringing together or separating natural objects, is done in virtue of the powers which they themselves possess as natural objects. 
Artificial things are, in fact, all produced by the action of that part of nature which we call mankind, upon the rest.

We talk of "making" a box, and rightly enough, if we mean only that we have shaped the pieces of wood and nailed them together; but the wood is a natural object and so is the iron of the nails. A watch is "made" of the natural objects gold and other metals, sand, soda, rubies, brought together, and shaped in various ways ; a coat is "made" of the natural object, wool; and a frock of the natural objects, cotton or silk. Moreover, the men who make all these things are natural objects.

Carpenters, builders, shoemakers, and all other artisans and artists, are persons who have learned so much of the powers and properties of certain natural objects, and of the chain of causes and effects in nature, as enables them to shape and put together those natural objects, so as to make them useful to man.

A carpenter could not, as we say, "make" a chair unless he knew something of the properties and powers of wood; a blacksmith could not "make" a horseshoe unless he knew that it is a property of iron to become soft and easily hammered into shape when it is made red-hot; a brickmaker must know many of the properties of clay; and a plumber could not do his work unless he knew that lead has the properties of softness and flexibility, and that a moderate heat causes it to melt.

So that the practice of every art implies a certain knowledge of natural causes and effects; and the improvement of the arts depends upon our learning more and more of the properties and powers of natural 
objects, and discovering how to turn the properties and the powers of things and the connections of cause and effect among them to our own advantage.

\section{Many Objects and Chains of Causes and} Effects in Nature are out of our reach.

Among natural objects, as we have seen, there are some that we can get hold of and turn to account. But all the greatest things in nature and the links of cause and effect which connect them, are utterly beyond our reach. The sun rises and sets; the moon and the stars move through the sky; fine weather and storms, cold and heat, alternate. The sea changes from violent disturbance to glassy calm, as the winds sweep over it with varying strength or die away; innumerable plants and animals come in being and vanish again, without our being able to exert the slightest influence on the majestic procession of the series of great natural events. Hurricanes ravage one spot; earthquakes destroy another; volcanic eruptions lay waste a third. A fine season scatters wealth and abundance here, and a long drought brings pestilence and famine there. In all such cases, the direct influence of man avails him nothing; and, so long as he is ignorant, he is the mere sport of the greater powers of nature.

\section{The Order of Nature : nothing happens} by Accident, and there is no such thing as Chance.

But the first thing that men learned, as soon as they began to study nature carefully, was that some events take place in regular order and that some causes 
always give rise to the same effects. The sun always rises on one side and sets on the other side of the sky; the changes of the moon follow one another in the same order and with similar intervals; some stars never sink below the horizon of the place in which we live ; the seasons are more or less regular; water always flows down-hill; fire always burns; plants grow up from seed and yield seed, from which like plants grow up again; animals are born, grow, reach maturity, and die, age after age, in the same way. Thus the notion of an order of nature and of a fixity in the relation of cause and effect between things gradually entered the minds of men. So far as such order prevailed it was felt that things were explained; while the things that could not be explained were said to have come about by chance, or to happen by accident.

But the more carefully nature has been studied, the more widely has order been found to prevail, while what seemed disorder has proved to be nothing but complexity; until, at present, no one is so foolish as to believe that anything happens by chance, or that there are any real accidents, in the sense of events which have no cause. And if we say that a thing happens by chance, everybody admits that all we really mean is, that we do not know its cause or the reason why that particular thing happens. Chance and accident are only aliases of ignorance.

At this present moment, as I look out of my window, it is raining and blowing hard, and the branches of the trees are waving wildly to and fro. It may be that a man has taken shelter under one of these trees; perhaps, if a:stronger gust than usual comes, a branch will break, 
fall upon the man, and seriously hurt him. If that happens it will be called an "accident," and the man will perhaps say that by "chance" he went out, and then "chanced" to take refuge under the tree, and so the " accident" happened. But there is neither chance nor accident in the matter. The storm is the effect of causes operating upon the atmosphere, perhaps hundreds of miles away; every vibration of a leaf is the consequence of the mechanical force of the wind acting on the surface exposed to it; if the bough breaks, it will do so in consequence of the relation between its strength and the force of the wind; if it falls upon the man it will do so in consequence of the action of other definite natural causes ; and the position of the man under it is only the last term in a series of causes and effects, which have followed one another in natural order, from that cause, the effect of which was his setting out, to that the effect of which was his stepping under the tree.

But, inasmuch as we are not wise enough to be able to unravel all these long and complicated series of causes and effects which lead to the falling of the branch upon the man, we call such an event an accident.

\section{Laws of Nature; Laws are not Causes.}

When we have made out by careful and repeated observation that something is always the cause of a certain effect, or that certain events always take place in the same order, we speak of the truth thus discovered as a law of nature. Thus it is a law of nature that anything heavy falls to the ground if it is 
unsupported; it is a law of nature that, under ordinary conditions, lead is soft and heavy, while flint is hard and brittle ; because experience shows us that heavy things always do fall if they are unsupported, that, under ordinary conditions, lead is always soft and that flint is always hard.

In fact, everything that we know about the powers and properties of natural objects and about the order of nature may properly be termed a law of nature. But it is desirable to remember that which is very often forgotten, that the laws of nature are not the causes of the order of nature, but only our way of stating as much as we have made out of that order. Stones do not fall to the ground in consequence of the law just stated, as people sometimes carelessly say; but the law is a way of asserting that which invariably happens when heavy bodies at the surface of the earth, stones among the rest, are free to move.

The laws of nature are, in fact, in this respect, similar to the laws which men make for the guidance of their conduct towards one another. There are laws about the payment of taxes, and there are laws against stealing or murder. But the law is not the cause of a man's paying his taxes, nor is it the cause of his abstaining from theft and murder. The law is simply a statement of what will happen to a man if he does not pay his taxes, and if he commits theft or murder; and the cause of his paying his taxes, or abstaining from crime (in the absence of any better motive) is the fear of consequences which is the effect of his belief in that statement. A law of man tells what we may expect society will do under certain circumstances; and a law of nature tells us what we may expect 
natural objects will do under-certain circumstances. Each contains information addressed to our intelligence, and except so far as it influences our intelligence, it is merely so much sound or writing.

While there is this much analogy between human and natural laws, however, certain essential differences between the two must not be overlooked. Human law consists of commands addressed to voluntary agents, which they may obey or disobey; and the law is not rendered null and void by being broken. Natural laws, on the other hand, are not commands but assertions respecting the invariable order of nature; and they remain laws only so long as they can be shown to express that order. To speak of the violation, or the suspension, of a law of nature is an absurdity. All that the phrase can really mean is that, under certain circumstances the assertion contained in the law is not true ; and the just conclusion is, not that the order of nature is interrupted, but that we have made a mistake in stating that order. A true natural law is an universal rule, and, as such, admits of no exceptions.

Again, human laws have no meaning apart from the existence of human society. Natural laws express the general course of nature, of which human society forms only an insignificant fraction.

I0. Knowledge of Nature is the Guide of Practical Conduct.

If nothing happens by chance, but everything in nature follows a definite order, and if the laws of nature embody that which we have been able to learn 
about the order of nature in accurate language, then it becomes very important for us to know as many as we can of these laws of nature, in order that we may guide our conduct by them.

Any man who should attempt to live in a country without reference to the laws of that country would very soon find himself in trouble; and if he were fined, imprisoned, or even hanged, sensible people would probably consider that he had earned his fate by his folly.

In like manner, any one who tries to live upon the face of this earth without attention to the laws of nature will live there for but a very short time, most of which will be passed in exceeding discomfort; a peculiarity of natural laws, as distinguished from those of human enactment, being that they take effect without summons or prosecution. In fact, nobody could live for half a day unless he attended to some of the laws of nature; and thousands of us are dying daily, or living miserably, because men have not yet been sufficiently zealous to learn the code of nature.

It has already been seen that the practice of all our arts and industries depends upon our knowing the properties of natural objects which we can get hold of and put together; and though we may be able to exert no direct control over the greater natural objects and the general succession of causes and effects in nature, yet, if we know the properties and powers of these objects, and the customary order of events, we may elude that which is injurious to us, and profit by that which is favourable.

Thus, though men can nowise alter the seasons or change the process of growth in plants, yet having 
learned the order of nature in these matters, they make arrangements for sowing and reaping accordingly; they cannot make the wind blow, but when it does blow they take advantage of its known powers and probable direction to sail ships and turn windmills; they cannot arrest the lightning, but they can make it harmless by means of conductors, the construction of which implies a knowledge of some of the laws of that electricity, of which lightning is one of the manifestations. Forewarned is forearmed, says the proverb; and knowledge of the laws of nature is forewarning of that which we may expect to happen, when we have to deal with natural objects.

\section{Science: the Knowledge of the Laws} of Nature obtained by Observation, Experiment, and Reasoning.

No line can be drawn between common knowledge of things and scientific knowledge; nor between common reasoning and scientific reasoning. In strictness all accurate knowledge is Science; and all exact reasoning is scientific reasoning. The method of observation and experiment by which such great results are obtained in science, is identically the same as that which is employed by every one, every day of his life, but refined and rendered precise. If a child acquires a new toy, he observes its characters and experiments upon its properties; and we are all of us constantly making observations and experiments upon one thing or another.

But those who have never tried to observe accurately will be surprised to find how difficult a business it is. Thẹre is not one person in a hundred who can 
describe the commonest occurrence with even an approach to accuracy. That is to say, either he will omit something which did occur, and which is of importance; or he will imply or suggest the occurrence of something which he did not actually observe, but which he unconsciously infers must have happened. When two truthful witnesses contradict one another in a court of justice, it usually turns out that one or other, or sometimes both, are confounding their inferences from what they saw with that which they actually saw. A swears that B picked his pocket. It turns out that all that A really knows is that he felt a hand in his pocket when $\mathrm{B}$ was close to him; and that $B$ was not the thief, but $C$, whom $A$ did not observe. Untrained observers mix up together their inferences from what they see with that which they actually see in the most wonderful way; and even experienced and careful observers are in constant danger of falling into the same error.

Scientific observation is such as is at once full, precise, and free from unconscious inference.

Experiment is the observation of that which happens when we intentionally bring natural objects together, or separate them, or in any way change the conditions under which they are placed. Scientific experiment, therefore, is scientific observation performed under accurately known artificial conditions.

It is a matter of common observation that water sometimes freezes. The observation becomes scientific when we ascertain under what exact conditions the change of water into ice takes place. The commonest experiments tell us that wood floats in water. 
Scientific experiment shows that, in floating, it displaces its own weight of the water.

Scientific reasoning differs from ordinary reasoning in just the same way as scientific observation and experiment differ from ordinary observation and experinent-that is to say, it strives to be accurate; and it is just as hard to reason accurately as it is to observe accurately.

In scientific reasoning general rules are collected from the observation of many particular cases; and, when these general rules are established, conclusions are deduced from them, just as in every-day life. If a boy says that "marbles are hard," he has drawn a conclusion as to marbles in general from the marbles he happens to have seen and felt, and has reasoned in that mode which is technically termed induction. If he declines to try to break a marble with his teeth, it is because he consciously, or unconsciously, performs the converse operation of deduction from the general rule "marbles are too hard to break with one's teeth."

You will learn more about the process of reasoning when you study Logic, which treats of that subject in full. At present, it is sufficient to know that the laws of nature are the general rules respecting the behaviour of natural objects, which have been collected from innumerable observations and experiments ; or, in other words, that they are inductions from those observations and experiments. The practical and theoretical results of science are the products of deductive reasoning from these general rules.

Thus science and common sense are not opposed, as people sometimes fancy them to be, but science is 
perfected common "sense. Scientific reasoning is simply very careful common reasoning, and common knowledge grows into scientific knowledge as it becomes more and more exact and complete.

The way to science then lies through common knowledge; we must extend that knowledge by careful observation and experiment, and learn how to state the results of our investigations accurately, in general rules or laws of nature; finally, we must learn how to reason accurately from these rules, and thus arrive at rational explanations of natural phenomena, which may suffice for our guidance in life.

\section{MATERIAL OBJECTS.-A. MINERAL BODIES.}

\section{The Natural Object Water.}

One of the commonest of common natural objects is water ; everybody uses it in one way or another every day; and consequently everybody possesses a store of loose information - of common knowledgeabout it. But, in all probability, a great deal of this knowledge has never been attended to by its possessor; and certainly, those who have never tried to learn how much may be known about water, will be ignorant of a great many of its powers and properties and of the laws of nature which it illustrates; and consequently will be unable to account for many things of which the explanation is very easy. So we may as well make a beginning of science by studying water. 


\section{A Tumbler of Water.}

Suppose we have a tumbler half-full of water. The tumbler is an artificial object $(\$ 5)$; that is to say, certain natural objects have been brought together and heated till they melted into glass, and this glass has been shaped by a workman. The water, on the other hand, is a natural object, which has come from some river, pond, or spring; or it may be from a water-butt into which the rain which has fallen on the roof of a house has flowed.

Now the water has a vast number of peculiarities. For example, it is transparent, so that you can see through it ; it feels cool ; it will quench thirst and dissolve sugar. But these are not the characters which it is most convenient to begin with.

I4. Water occupies Space ; it offers Resistance; it has Weight; and is able to transfer Motion which it has acquired; it is therefore a form of Matter.

The water, we see, fills the cavity of the tumbler for half its height, therefore it occupies that much space, or has that bulk or volume. If you put the closed end of another tumbler of almost the same size into the first, you will find that when it reaches the water, the latter offers a resistance to its going down, and unless some of the water can get out, the end of the second tumbler will not go in. Any one who falls from a height into water will find that he receives a severe shock when he reaches it. Water therefore offers resistance.

If the water is emptied out, the tumbler feels much 
lighter than it was before; water, therefore, has weight.

And, finally, if you throw the water out of the tumbler at any slightly supported object, the water hitting against it would knock it over. That is to say, the water being put in motion is able to transfer that motion to something else.

All these phenomena, as things which happen in nature are often called, are effects of which water, under the conditions mentioned, is the cause, and they may therefore be said to be properties $\left(\S_{4}\right)$ of water.

All things which occupy space, offer resistance, possess weight and transfer motion to other things when they strike against them, are termed material substances or bodies, or simply matter. Water, therefore, is a kind, or form, of matter.

\section{I5. Water is a liquid.}

You will easily observe that, though water occupies space, it has mo definite shape, but fits itself exactly to the figure of the vessel which holds it. If the tumbler is cylindrical, the contour of the surface of the water will be circular when the tumbler is held vertically, and will change, without the least break or interruption, to more and more of an oval when the tumbler is inclined; and, whatever the shape of the vessel into which you pour it, the sides of the water always exactly fit against the sides of the vessel. If you put your finger into the water you can move it in all directions with scarcely any feeling of obstacle. If you pull your finger out there is no hole left, the water on all sides rushing together to fill up the space that was occupied by the finger. You cannot take up a handful of 
water, for it runs away between your fingers, and you cannot raise it into a permanent heap. All this shows that the parts of water move upon one another with great ease. The same fact is illustrated if the tumbler is inclined, so that the level of the surface rises above the edge of the tumbler on one side, and the water is therefore to some extent unsupported by the tumbler at this point. The water then flows over in a stream and falls to the ground, where it spreads out and runs to the lowest accessible place, or gradually soaks up into crevices.

Nevertheless, although the parts of the water thus loosely slip and slide upon one another, yet they hold together to a certain extent. If the surface of the water is just touched with the finger, a little of it will adhere; and if the finger is then slowly and carefully raised, the adjacent water will be raised up into a slender column which acquires a noticeable length before it breaks. So, in the early morning, after heavy dew, you may see the water upon cabbage-leaves and blades of grass in spherical drops, the parts of which similarly hold together.

Material substances, the parts of which are so movable that they fit themselves exactly to the sides of any vessel which contains them, and which flow when they are not supported, are called fluids; and fluids - the parts of which do not fly off from one another, but hold together as those of water do, are called liquids.

Water therefore is a liquid.

\section{Water is almost incompressible.}

It has been seen that water, like every other 
material substance, resists the intrusion of other matter into the place which it occupies. But many things, though they resist, can be easily squeezed or compressed into a smaller volume. This, however, is not the case with water, which like other liquids, is almost incompressible : that is to say, an immense pressure is needful to cause its volume to diminish to any appreciable extent. It may seem strange that anything so apparently yielding as water should yet be almost as difficult to squeeze as so much iron; but the apparent yieldingness of water is due to the ease with which it changes its shape ; and, if water is prevented from changing its shape, it is very difficult to drive its parts closer together. It has been ascertained that if water is confined in a closed space, a pressure amounting to fifteen pounds on the square inch diminishes its volume by only $\frac{1}{20000}$ th part. Take a common syringe, and having seen that the plug or piston fits the cylinder of the syringe well, put the nozzle into water and draw the piston up. Then turn the nozzle upwards and push upon the piston till a little of the water squirts out, so as to make sure that the cylinder contains nothing but water. Now put your finger on the opening of the nozzle firmly, so as to stop any water from passing out, and then try to push the piston down. You will find that you cannot make it stir without great force ; and, if the piston moves appreciably, it will be because some of the water has escaped by the sides of the piston. In fact, if the piston presented a square inch of surface, and fitted accurately, and the column. of water in the cylinder were one inch long, it must be pressed down by a weight of 30,000 pounds (about thirteen tons) to make it move one-tenth of an inch. 


\section{The Meaning of Weight.}

Let us next consider the property of weight. We say that anything has weight when, on trying to lift it from the ground, or on holding it in the hand, we have a feeling of effort. Or again, if anything which is supported at a certain height above the ground, falls when the support is taken away, we say that it has weight. Now the ground merely means the surface of the earth; and, as all bodies which possess weight fall directly towards the surface of the earth when they are not kept away from it by some support, we may say that all bodies which have weight tend to fall in this way. And it does not matter on what part of the surface of the earth you make the experiment. Rain consists of drops of water, and it does not matter whether we watch a shower in calm weather here, or in New Zealand; the drops fall perpendicularly towards the ground. But we know that the earth is a globe and that New Zealand is at our antipodes, or on the opposite side of the globe to England. Hence if two showers are falling at the same time, one in New Zealand and one here-the drops must be falling in opposite directions, towards one another; that is, towards the centre of the earth which lies between them. In fact, all bodies which have weight tend to fall towards the centre of the earth-that is to say they fall in this way if there is nothing to prevent them; and when we speak of weight we mean this tendency to fall. To call anything heavy, is the same as saying that we fully expect that, if there is nothing to support it, it will fall to the ground; or that if we support it ourselves we shall be conscious of effort. 


\section{Gravity and Gravitation.}

The word gravity, when it was tirst used, had exactly the same meaning as weight; and a body which has weight is said to gravitate towards the centre of the earth. But gravity has now acquired a much wider sense than weight. For an immense number of careful observations and experiments have established the general rule, or law of nature, that every material substance tends to approach every other material substance, just in the same way as a drop of rain falls towards the earth; and, in fact, that any two portions of matter, whatever the nature of that matter may be, will move towards one another if there is nothing to prevent them from doing so.

To make this clear, let us suppose that the only material bodies in the universe were two spherical drops of water, each a tenth of an inch in diameter. Each of these drops would have the same bulk as the other, and would be a quantity of matter exactly equivalent to the other. Then, however great the distance which separated these two drops, they would begin to approach one another; and, each moving with gradually increasing swiftness, they would at length meet in a point exactly half-way between the positions which they at first occupied. But if the bulk of one drop were greater than that of the other drop, then the larger would move more slowly, and the point of meeting would be by so much nearer the larger drop. It follows that, if the one body of water were as big as the earth and the other remained of its original size, no bigger than a rain-drop-the motion of the large mass towards the small one would be an inconceivably minute fraction of the total 
distance travelled over. It would appear as if the large body were perfectly still and drew the small body to itself.

This is just what happens when a single drop of water falls from a cloud, say through a distance of a mile, to the earth. The earth really moves towards it, just as it moves towards the earth, on the straight line which joins the centres of the two. But the length of this line which each travels over is inversely proportional to the quantity of matter in each, that is to say is the less the bigger the quantity. So that we have a rule-of-three sum. As the quantity of matter in the earth is to that in a raindrop, so is a mile to the distance travelled over by the earth. And if any one worked out this sum, he would find that the fourth term of the proportion would be an inconceivably minute fraction of an inch. For all practical purposes, therefore, we may consider the earth to be at rest in relation to all falling bodies, inasmuch as the quantity of matter in any falling body is insignificant, in comparison with that contained in the earth.

What is true of water is true, so far as we know, of all kinds of matter, and we therefore say that it is a law of nature that all kinds of matter possess gravity; that is to say, that of any two, each tends to move towards the other, at a speed which is the slower the greater the quantity of matter it contains in proportion to that which the other contains; and this speed gradually becomes quicker as the two bodies approach.

What is usually called the law of gravitation is a statement of the same observed facts in another and more complete fashion. (See Physics Primer:) 


\section{I9. The cause of Weight: Attraction :} Force.

We know nothing whatever of the reason why bodies possess weight. Bodies do not fall on account of the law of gravitation $(\$ 9)$; nor does their gravity explain why they fall. Gravity, as we have seen, is only a name for weight, and the law of gravitation is only a statement of how bodies approach one another, not why they do so.

It is often said that gravitation is attraction, and that bodies fall to the earth because the earth attracts them. But the word "attract" simply means to "draw towards," and "attraction" means nothing but "drawing towards;" and to say, when two bodies move towards one another, that they are "drawn towards" one another, is simply to describe the fact and makes us no whit wiser than we were before. On the contrary, unless we take great care, it may make us a little less wise. For the words "drawing towards" are so closely associated with ropes and hooks and the act of pulling, that we are easily led to fancy the existence of some analogous invisible machinery in the case of mutually attractive bodies.

Again, gravitation is spoken of as a force; and as the word force is in very common use, let us try to make out what we mean by it. A man is said to exert force when he pushes or pulls anything so as either to exert pressure upon it or to put it in motion. A wrestler's force is proved by his hug; a bowler's force is shown by the swiftness of motion of the ball.

Force, then, is the name which we give to that which causes or, in the case of pressure, tends to cause, motion. The force of gravity therefore means 
the cause of the pressure which we feel when bodies which possess gravity are supported by our bodies, and the cause of their movement towards the centre of the earth, when they are free to move. But it is exactly about the cause of these phenomena that we know nothing whatever.

A good deal of mischief is done by the inaccurate use of such words as attraction and force, as if they were the names of things having an existence apart from natural objects, and from the series of causes and effects which are open to our observation; while they are, in reality, merely the names of the unknown causes of certain phenomena. And it is worth while to take pains to get clear ideas on this head at the outset of the study of science.

Let us remember then that, so far as we know, it is a law of nature, that any two material bodies, if they are free to move, approach one another with gradually increasing swiftness; and that the space over which each travels before the two meet, is inversely proportional to the quantity of matter which it contains. Attraction of gravitation is a name for this general fact; weight is the name for the fact in the case of terrestrial bodies; force is a name which we give to the unknown cause of the fact. The fact is that which it is important to know. The names are of no great consequence so long as we recollect that they are merely names and not things.

20. The Weight of Water is Proportioned to its Bulk.

We must next consider, not weight in general, but the weight of water. We say that a tumbler full of 
water is heavier than an empty tumbler, because the full tumbler gives us a greater feeling of effort when we lift it than the empty tumbler does. The more water there is in the tumbler the greater is the effort. A pail full of water requires still more effort, though the empty pail feels quite light; and, when we come to deal with a large tub full of water, we may be unable to stir it, though the empty tub could be lifted with ease. Thus it seems that the greater the bulk of water the more it weighs, and the less the bulk the less it weighs. But then a single drop of water in the palm of the hand seems to weigh nothing at all. However, this clearly cannot be, for the drop falls to the ground readily, and therefore it must have weight. Moreover, a few thousand drops would fill the tumbler, and if a thousand drops weigh something, each drop must have a thousandth of that weight. The fact is that our feeling of effort is a very rough measure of weight, and does not enable us to compare small weights, or even to perceive them if they are very small. To know anything accurately about weight we must have recourse to an instrument which is contrived for the purpose of measuring weights with precision.

\section{The Measuring of Weights. The Balance.}

Such an instrument is the balance or scales, which you may see in every grocer's shop. It is composed of a beam which moves easily on a pivot fixed to its middle, and which has a scale-pan attached to each end. So long as both scale-pans are empty the beam is horizontal; but if you put anything which has 
weight into one, that one goes down and the other rises. If now you either pull or push the empty scale downwards, the beam may be brought into the horizontal position again, and the effort required to bring it into the horizontal position will be the greater, the greater the weight of the body in the opposite scale. An ounce in the one scale is easily raised by the pressure of a finger in the other. A pound requires more effort; ten pounds needs putting out the strength of the arm; to raise fifty pounds involves still more exertion; while a couple of hundred. weight will not be stirred by the strongest push or pull upon the empty scale.

Suppose that, instead of pressing down the empty scale, you put something that has weight into it; then, as soon as this weight is equal to that in the other scale, the beam will become horizontal. In fact, one scale has just as much tendency to move towards the centre of the earth as the other has, and as neither can go down without pulling the other up, they neutralise one another. It comes to the same thing, as if two boys of equal strength were pulling one against the other; so long as the pulls in opposite directions are equal, of course neither boy can stir; while the smallest addition of strength to one enables him to pull the other over.

22. The Weight of the same Bulk or Volume of Water is Constant under the same conditions. Mass. Density.

Now let two graduated thin glass measures be put into the two scales, and made to counterpoise one another exactly. Then, if even a single drop of 
water is put into the one measure the scale will descend, if the balance is a good one; showing that the drop has weight. If the measures are graduated accurately, then whatever volume of water is put into one, an exactly similar volume of the same water must be put into the other to make the beam level. This obviously means that the same volume of water under the same circumstances always has the same weight.

In $\S_{1} 8$ it was said that bodies tend to move towards one another with a relative velocity ${ }^{1}$ which is inversely proportional to the quantity of matter which they contain. But how are we to measure quantity of matter? Is it to be estimated by the space which it occupies; that is, by its volume? or are we to estimate the quantity of matter in a body by its weight? You will soon learn that the volume of all bodies is constantly changing in correspondence with the changes in the pressure exerted by other bodies, but more especially in correspondence with the changes of temperature to which they are subjected; while the weight of the same body, at the same, point on the earth's surface, never alters. Hence we may take the weight of a body as a measure of the quantity of matter which it contains ; and it follows that, for the same weight, the larger the volume of a body the less matter it contains proportionally to its volume, and the less the volume, the more matter it contains. The

1 Velocity, or swiftness, is measured by the distance over which a body travels in a given time. Of two bodies, one of which travels through one foot in a second, while the other travels through two feet, the latter has the greater relative velocity. 
proportion of its weight to its volume gives us the density of a body.

Now what is true of water is true of all other bodies or material substances. Suppose that one of the measures is emptied and replaced, the beam may be brought to the horizontal position again by means of a piece of lead cut to exactly the right size. The piece of lead will thenceforth furnish an exactly corresponding or equivalent weight for so much water; and pieces of iron or brass, which counterpoise the lead, will also be equivalents of the weight of the water, or of the lead, or of one another. But the pieces of lead, iron, or brass will obviously be of much less volume or bulk than the water which they counterpoise. Here it follows that the densities of these metals, or the quantity of matter contained in the same volume, must be much greater than in the case of water.

What are called weights in commerce are pieces of lead, or iron, or brass exactly equivalent in weight to a certain bulk of water under certain conditions. An imperial gallon of water thus weighs ten pounds, and therefore an imperial pint weighs a pound and a quarter.

23. Equal Volumes of Different Things under the same circumstances, have Different Weights : the Density of Different Bodies is Different.

The important fact which has just been alluded to must be considered more fully. We have seen that an imperial pint measure gives us the space which is taken up by as much water as weighs a pound and a quarter; and this space is the bulk or volume of that 
weight of water. But if you take an ordinary pound weight and a quarter-pound weight, and put them into an imperial pint measure, you will find that, instead of filling it, they take up only a very small portion of the space in its interior, or in other words, of its capacity. Thus the volume of a pound and a quarter of lead, or of iron, or of brass, is very much less than the volume of the same weight of water ; that is to say, the metals are denser than water; the same volume has greater mass or more gravity. Or, to put the case in another way, fill the tumbler with which we began half full of water, making a mark on the side exactly at the level of the top of the water. Then place it in one scale of a balance, and counterpoise it with weights in the other. Next, pour out the water, and after drying the tumbler, fill it with fine sand carefully up to the mark. The volume of sand will be equal to the volume of water. But now the same weights will no longer counterpoise it, and you will have to put more weights in the opposite scale. Volume for volume, therefore, sand is heavier than water. Throw out the sand, and put in sawdust in the same way, and you will find that a less weight than was necessary to counterpoise the water counterpoises the sawdust. Volume for volume, therefore, sawdust is lighter than water. Experiment in the same way with spirit and oil, and they will be found to be lighter than water, while treacle will be heavier, and quicksilver very much heavier than water.

\section{The Meaning of Heavy and Light- Specific Gravity. \\ We are in the habit of using the words heavy and}


light rather carelessly. We call things that are easily lifted light, and things that are hard to lift, heavy. We say that sand, which is blown about by the wind, is light, and that a block of wood is heavy, and yet we have just seen that sand is heavier, bulk for bulk, than wood. In order to get rid of this double meaning, the weight of a volume of any liquid or solid, in proportion to the weight of the same volume of water at a known temperature and pressure, is called its specific gravity. Water being taken as $\mathbf{r}$, anything a volume of which is twice as heavy as the same volume of water is said to have the specific gravity 2 ; if three times, 3 ; if four and a half times, $4 \cdot 5$, and so on. Thus the specific gravity of any liquid or solid expresses: its density in proportion to that of water under the same conditions. Sawdust, oil, and spirit have a less specific gravity than water, while treacle, sand, and quicksilver have a greater specific gravity. In this sense, the former three substances are light, while the latter three are heavy.

25. Things of greater Specific Gravity than Water sink in Water; Things of less Specific Gravity float.

Here are two tumblers of water.- Throw some sand into one and some sawdust into the other. What happens? The sand sinks to the bottom, the sawdust floats at the top. We may stir them up as we like, but the sand will tumble to the bottom and the sawdust, as obstinately, rise to the top. Thus that which is lighter than the water floats, and that which is heavier (bulk for bulk) sinks. So, if we pour 
some oil into the water, it floats, and if we pour some coloured spirit in carefully, it also floats ; while treacle and quicksilver sink to the bottom, just as the ironfilings do.

We saw that the iron-filings sank, because iron is heavier than water. Here is a piece of the thin tinned sheet-iron that they make tin boxes of. What will happen if we drop it into the water? It is heavier than water, bulk for bulk, and therefore it will sink as you see it does.

But now here is a "tin" canister made of this very same tinned sheet-iron. We drop that into the water, and you see it does not sink at all, but floats at the top as if it were made of cork. Here is a perplexity. We were sure just now that iron is heavier than water, and here is an iron box floating! Is this an exception to the law? Not at all; for what we said was that a thing would float if it were lighter, bulk for bulk, than water. Now let us weigh the tin box, and having weighed it let us next try to find out how much the same bulk of water weighs. This may be done very simply, for the walls of the box are very thin, so that the inside of the box is very nearly as large as the whole box. Consequently, if we fill the box with water, and then weigh the water, we shall find out, very nearly, what is the weight of a bulk of water as great as that of the box. But if we do this, we shall find that the water which was contained in the box, weighs very much more than the box does.' So that, bulk for bulk, the box, although it is made of iron, is really lighter than water, and that is why it floats.

You will all have heard of the iron ships which are now so common, and you may have wondered how it 
is, that ships made of thick plates of iron riveted together, and weighing many thousand tons, do not go to the bottom. But they are nothing but our tin canisters on a great scale, and they float because each ship weighs less than a quantity of water of the same bulk does.

It is because of this property of water to bear up things lighter than itself, and because of that other property of being easily moved which the particles of water have, that the sea, and rivers, and canals, are such great highways for mankind.

For there is nothing so heavy that it may not be made to float in water, if the box which holds it is large enough to make the weight of the whole less than the weight of the same bulk of water. And then, having once got the weight to float, the particles of water are so easily moved, that the force of the winds, or of oars, or of paddles, readily causes it to slip through the water from one place to another.

26. A Body which Floats in Water always occupies as much Space beneath the level of the Surface of the Water as is equal to the Volume of Water which weighs as much as that Body; in other words, it displaces its own Weight of Water.

A cubic inch of water weighs about $25^{2}$ grains and a half. Suppose that the tin box in the previous experiment was square, and had the bulk of roo cubic inches, then the weight of a corresponding volume of water would be 25,250 grains. If the box weighed 8,416 grains, just a third of its bulk would be immersed; if 
I 2,625 grains, half; if 16,832 grains, it would sink twothirds of its volume, and so on. Or, if, when the box is floating, you make a mark upon its side at the exact level of the surface of the water, the bulk of that portion of the box which lies below the water-level can be ascertained. Suppose it to be thirty cubic inches, then the weight of the box will be $30 \times 25^{\circ} 5$ or 7575 grains. Hence it may be said that the immersed part of a floating body takes the place of the water which it displaces, and, as it were, represents it. If you press downwards upon the floating box, there is a feeling of resistance as it descends, and when the pressure is taken off, the body immediately rises again. Hence the water presses upwards against the bottom of the floating body. But it also presses against the sides, for if the sides of the box are very thin they will be driven in. If a thin empty bottle is tightly corked and lowered into deep water the cork will be driven in, or else the bottle will be crushed.

\section{Water Presses in all Directions.}

Thus water presses in all directions upon things which are immersed in it.

If a long wooden or metal pipe, placed vertically, has its lower end stopped with a cork which does not fit very tightly, and water is poured into the top of the tube, the water will at first fill the part of the tube above the cork, and its weight will exert a certain pressure on the cork. In fact, if the end of the tube is stopped by applying the palm of the hand closley against it, the downward pressure of the water will have to be overcome by a certain amount of effort. As the water accumulates, this downward 
pressure will become greater and greater until the hand is driven away, or the cork is forced out, and the water falls to the ground. The pressure in this case is the same as the weight of the water, and the cork would have been driven out equally well by a rod of lead of the same weight.

Suppose the tube to be square, and that the inside of the square measures exactly one inch each way. Then an inch of leight of the tube will hold exactly one cubic inch of water. Since one curic inch of water weighs 252 grains and a half,.. as much water as will fill the tube about two feet three inches and a half high, will weigh a pound $(7,000$ grains), and fifteen pounds of water will fill such a tube between thirty-three and thirty-four-feet high. And these respective iveights measure the pressure of two columns of water, one twenty-seven and a half inches high, and the other nearly thirty-four feet high, on a square inch of the surface on which they rest.

The specific gravity ( $\$ 24)$ of lead is 11.45 ; in other words it is about eleven and a half times denser than water. Therefore if a bar of lead cut square and one inch in the side, and rather less than $\frac{T}{11}$ th of the height of a column of water, is slipped into the tube in place of the water, it will exert the same pressure on the bottom.

And now comes a difference between the lead and the water," which depends on the fluidity of 'the latter. The lead exerts no pressure on the sides of the tube, but the water does. If a sinall hole is cut in the' side of the tứ close to the bottom, and stopped with a cork, the lead will not press uron the cork. But if the column of water is high enough, 
the cork will be driven out with as much force as before, so that the water presses just as much sideways as downwards. It is easy to satisfy oneself of this by inserting a long glass tube, with its lower end bent at right angles and fitted with a cork, into the side of the wooden pipe. The water will at once rise in the tube to the same height as it has in the pipe. Whence it is obvious that the pressure of the water on any point of the side is exactly equal to the vertical pressure at that point; for the pressure outwards is exactly balanced by that of the vertical column in the tube inwards. - The water in a watering-pot always stands at the same level in the can and in the spout.

If a glass tube is bent into the shape of a $U$, and water is poured into it, the water will always stand at the same level in the two legs of the tube, whatever the shape of the bend may be, or the relative capacities of the two legs, or the inclination of the tule. And this must needs be so, for the force with which the water tends to flow out of the one half of the arrangement depends on the vertical height ${ }^{1}$ of the surface of the water above the aperture of exit; so that any column of equal vertical height must balance it.

That a column of water will stand at exactly the same level as any other with which it communicates, may be seen still more simply by placing a glass tube, open at each end, in a basin of water. However the tube may be inclined or bent; whether its lower end is

$r$ Vertical height is the height measured atong a line drawn from the surface of the water perpendicularly to the surface of the earth. A plumb-line is a string to one end of which a weight is attached and thus hangs suspended. If the other end of the line is brought opposite the surface of the water the direction of the string answers to the line of vertical height. 
wide or narrow, the column of water inside it will be at exactly the same level as the water outside it. Yet, of course, the rigid glass walls of the tube cut off all communication between the column of water inside it and the rest, except at the bottom.

In a well-ordered town, water is supplied to every house and can be drawn from taps placed in the highest stories. 'These are fed by pipes which lead from a cistern at the top of the house. This water is brought from a large pipe, or main, in the street, by a smaller house-pipe, which is often made to twist about in various directions before it reaches the cistern at the top of the house into which it delivers the water. If you followed the main, you would find that it took a long course up and down, beneath the pavement. of the streets, until at last it reached the waterworks. Here you would find that the main was connected with a reservoir ; and either this reservoir is at a greater height than any of the cisterns into which the water is delivered, or there is some means of pumping the water from it to that height on its way to the main. Thus the reservoir, the main, and the house-pipe form one immense $\mathrm{U}$-tube, and the water in the house-pipe tends to rise to the same level as that of the water in the reservoir, and hence flows into the cistern when the supply-pipe is open.

\section{The Transference of Motion by Moving Water : the Momentum of Moving Water.}

Suppose a wooden vat with a horizontal tap, the sectional area ${ }^{1}$ of the tube of which is one square inch,

1 The sectional area of a tube is the surface occupied by its cavity when it is cut across. It would be represented by the 
inserted close to the bottom, to be filled with water up to roo inches above the tap. Then supposing the tap to be shut, the pressure upon its sectional area will be 25,250 grains, or rather more than three pounds and a half-and there is the same pressure on every square inch of the bottom of the vat.

If the tap is now turned, the water nearest to it being unsupported on its outer side, the pressure on the inner side sets it in notion, and it flows out in a stream. At first the stream shoots out violently and the water is carried to a long distance. That is to say, the weight of the column of water roo inches. high acts as a force, or cause of motion, upon the water nearest the tap, and this water is forced out with a velocity depending on that force in a horizontal direction. Now suppose that you take a common toy cup-and-ball and bring the ball into the way of the stream of water. The stream will at once strike the ball and drive it in the same direction as that which it is itself taking. The power which the moving water has of transferring or communicating motion to a body which is at rest, but free to move as the ball is, is due to its momentum. The greater the mass of the stream and the more rapidly it moves, the more motion will it communicate to the ball, or the heavier the ball it will move. Close to the mouth of the tap the direction of the stream is horizontal; but it very soon begins to bend downwards, and describing a rapid curve, comes to the ground. It does this for just the same reasons that a stone thrown horizontally describes a curve, and at surface of a piece of cardboard, like the wad of a gun, just large enough to go into the tube. 
length strikes the ground; and, in fact, the stream may be regarded as so much water thrown horizontally.

These reasons are two: firstly, as soon as the water has left the tap it is an unsupported heavy body; and, as such, it begins to fall to the ground. Secondly, the momentum of the water is continually being diminished by the resistance of the air through which it passes. For, although the air which surrounds us is so thin and movable a body that we ordinarily take no notice of it-the fact that it offers resistance to bodies which move through it is easily observed; as, for example, in using a fan. The water has to overcome this resistance, and its momentum is proportionally diminished.

If, when the water leaves the tap, the air and gravitation were alike abolished, the water, keeping its momentum; would travel for ever in the same direction.

As the water runs out, it will be observed that the velocity of the stream becomes less and the curve which it describes sharper, so that it comes to the ground sooner; and finally, when the vat is nearly empty, the stream falls nearly vertically downwards. The reason of this is that the level of the top of the water is gradually lowered; consequently, the height of the column which presses on the water close to the tap is gradually lessened, and therefore its weight is diminished. But this weight or pressure is the cause of the motion of the water, and as the cause diminishes the effect of that cause must diminish. Therefore the momentum of the water is gradually lessened and it is carried less and less far horizontally in the time which it takes to fall to the ground; 
until finally, it acquires no appreciable horizontal motion at all, and so falls vertically downwards from the mouth of the tap.

\section{The Energy of Moving Water.}

If a short pipe bent at right-angles like the letter $L$ is fitted by one arm on to the end of the tap, while the other is turned vertically upwards, and the vat is full as before; when the tap is turned, the water will shoot up into the air, and after rising for a certain distance will stop; and then fall. In fact we shall have a fountain.

Observe the difference between the vertical jet of water and the horizontal jet. If we leave the resistance of the air out of consideration, the water in the horizontal jet has no obstacle to overcome; and it might go on for ever; if its weight did not gradually cause its path to become more and more bent towards the earth, against which it eventually strikes.

When the jet is vertical the case is altered. The water thrown up vertically constantly tends to fall down vertically, as any other heavy body would do, and its momentum has to overcume the obstacle of its gravity. Any given portion of the water is, in fact, acted upon by two opposite tendencies, momentum $X$ urging it up, and gravity pulling it down. Now if two equal tendencies exactly oppose one another, the body upon which they act does not move at all; while, if one is stronger than the other, the body moves in the direction of the stronger.

Thus a portion of water which has just left the spout shoots up, because the velocity with which it is impelled upwards is sufficient to carry it through a 
greater space in a given time, say a second, than that through which its gravity would, in the same time, impel it downwards.

But the distance which the water will travel during this second will be the difference between the distance which it yould have ascended if there had been no gravity forcing it down, and the distance which it would have descended if there had been no momentum driving it up; and, at the end of the second, the rate of its motion upwards, or its velocity, will be proportionally slower. Thus, at the end of the first second, the water has spent a certain portion of its momentum in overcoming its gravity. And as there is nothing to make good the loss, it would, if left to itself, travel more slowly, or over a less distance, in the second second than it tended to do in the first. But though the momentum of the water is diminished, its gravity, weight, or tendency to fall downwards, for a given distance in a second, remains exactly what it was, and operates in the course of the second second to exactly the same extent as in the first. Hence, at the end of the second second, the distance through which the water travels upwards is still smaller, and its velocity is still more diminished. It is obvious that, however great the disproportion between momentum and gravity to start with, gravity must gain the day in the long run under these circumstances. The store of momentum will be used up; and, after a momentary rest, the water, reduced to the condition of a body without support, will begin to be carried downwards by the unopposed action of gravity.

The case is similar to that of a boy sculling a boat, the bows of which are suddenly seized and the boat 
thrust violently backwards by a strong man. The boat will go stern-foremost rapidly, at first, but every stroke of the boy's oar at the stern will retard its backward motion ; until, at length, the stock of momentum conferred upon it by the man's thrust will be completely exhausted in working against the boy, and the boat, after a momentary rest, will resume its onward course. The distance to which the boat will be propelled backwards will evidently depend upon the amount of muscular power which the man, as it were, suddenly capitalizes in the boat, and which the boat then slowly pays out.

We call people who possess much muscular or other power energetic; and we estimate their energy by the obstacles they overcome, or, in other words, by the work they do. In the present illustration the man's energy would be measured by the distance to which the boat was propelled before it stopped.

It is easy to transfer this conception of energy, as the power of doing work, to inanimate things; and thus, when a body in motion overcomes any kind of obstacles in its way, parting with its momentum and more or less coming to rest in the process, we say that it has energy and that it does work.

The energy of moving water is thus measured by the intensity of the opposing forces which it can overcome multiplied into the distance which it can travel before that energy is exhausted; that is to say, by the work it does before it is itself reduced to a state of rest. In the case under consideration, the energy by which gravity is overcome, for a greater or less time, depends upon the velocity of the stream; and this again depends upon the height of the water in the vat 
above the tap. Just as the energy of the horizontal stream diminished as the level of the water became lower, so does the energy of the vertical stream diminish. Hence, as the vat empties, the jet becomes shorter and shorter, until at last it sinks down to nothing.

The energy of moving water makes it, under some circumstances, one of the most destructive of natural agents ; and, under others, one of the most useful servants of man. A stream is water falling down hill with a velocity depending upon the inclination of its.bed. As it falls it acquires momentum and, hence, energy'; and thus a mountain stream, suddenly swollen by rain or melting snow, will tear away masses of rock and sweep everything before it. Nothing can look softer or more harmless than a calm sea, but if the wind sweeping over its surface puts the water in motion, it strikes upon the shore with terrific force ; and its energy is expended in throwing up great waves; which lift vast blocks or drive masses of shingle up the beach.

In all kinds of watermills it is: the energy of more or less rapidly falling water which is turned to account. The water is made to flow against buckets or floats attached to the circumference of a wheel. Each bucket or float is therefore an obstacle to which the water transfers some of its own motion; it moves away and thus makes the wheel to which it is fastened turn. But the turning of the wheel brings a new obstacle in the way of the stream. This is treated in the same fashion, and the wheel-turns still further, thus introducing another obstacle in the way of the stream upon which the same effect is produced.:- Thus each float, or bucket, is a means by which some of the momentum 
of the stream is, as it were, caught and transferred to the water-wheel, which consequently turns round with a.certain velocity:

But this water-wheel is now a mass of matter in motion, and therefore itself contains a store of energy or power of doing work. If a cord with a weight at the end of it were fastened to the axle of the wheel, the cord would be wound upon the axle, and the weight could be raised, or, in other words, so much work would be done by the turning of the wheel; and we should thus have a rough measure of the amount of energy which had been given up by the stream to the wheel.

The machinery of the mill is simply a set of contrivances for transferring the energy stored up in the water-wheel to the place in which work has to be done. In a flour-mill, for example, a series of wheels carries it from the water-wheel to the grindstones, which it sets in motion.

\section{The Properties of Water are Constant.}

If, whenever there is a shower, you catch some rain. water, you will find that it possesses all the properties which have been described. It will be found to be an almost incompressible liquid, an imperial pint of which weighs about a pound and a quarter. It would make no difference if the rain-water were collected in Africa or in New Zealand ; or if it had been obtained centuries ago and kept bottled up ever since. And there is every reason to believe that rain-water will have exactly, the same properties a hundred or a thousand years hence. "So far as the properties of 
rain-water are concerned the order of nature is constant.

This however is by no means the same thing as saying that the properties of water are always the same. In fact the properties of the substance, water, vary immensely according to the conditions to which it is exposed; but, under the same conditions, they are the same, so that we may still say that, so far as water is concerned, the order of nature is constant.

\section{Increase of Heat at first causes Water to Increase in Volume.}

It has been seen that a certain weight of water always has the same volume under the same conditions. The most important of these conditions is the heat or cold to which it is exposed. Water which has stood for some time in a warm room becomes less in volume, or contracts, if it is taken into a cool place; while its volume increases, or it expands, if it is made hot. The same thing is true of quicksilver, of spirit, and of liquids in general. A thermometer is simply a small flask-the bulb-with a long and narrow neck-the tube-filled with as much mercury or spirit as will rise a short distance into the neck. If the liquid in the bulb is warmed, its volume is increased and it overflows into the tube, increasing the height of the column of liquid in the tube. If, on the other hand, the liquid in the bulb is cooled, its volume is diminished; and, as it shrinks, the column of liquid in the tube flows back into the bulb, and the level of the top of the column is lowered.

If a mark is made on the tube, or on a scale fixed to it, at the point which the liquid reaches when the 
bulb is placed in boiling water; and another mark at the point to which it sinks when the bulb is in melting ice; and the space between the two marks is divided into 180 equal parts, each of these parts is what is called a "degree" in the thermometers ordinarily used in this country (called Fahrenheits). And if the boiling-point is counted as $212^{\circ}$ the freezing-point must be $32^{\circ}(212-32=180)$. With the same amount of heat the fluid in the tube always stands at the same degree, and hence the instrument measures tem: perature.

That hot water is lighter than cold is easily seen when a bath is filled from two taps, one of hot and one of cold water, which run at the same time. Unless care is taken to stir the water, the top of the bath will be very much hotter than the bottom. Thus, an imperial pint of water weighs a pound and a quarter only at a certain temperature or degree of warmth, namely at $62^{\circ}$; if it is made hotter its volume increases, and therefore its specific gravity diminishes.

It was for this reason that in $\S 22$ the weight of the same volume of water was said to be constant under the same conditions; and, of course, the same qualification must be borne in mind when we speak of the weight of a cubic inch of water being about $25^{2}$ and a half grains. Its weight is in fact $25^{2} .45$ grains only when Fahrenheit's thermometer stands at $62^{\circ}$-but as this is the temperature of ordinary mild weather, and the expansion or contraction of water for a degree about this temperature amounts to less than $\frac{1}{3000}$ th of its volume, the weight of a cubic inch may for all practical purposes be taken as 252 and a half grains. 


\section{Increase of Heat at length causes Water to become Steam.}

Thus a change is effected in the properties of water by heating it ever so little. - If it is more strongly heated a still greater change takes place. You know what happens when a saucepan containing water is put on the fire. The water gets hotter and hotter, then it bejgins to simmer, and finally, when it reaches $22^{\circ}$, it boils away into steam, which passes into the air and disappears. If the boiling is carried on long enough all the water vanishes. It looks at first as if the water had been destroyed by the heat. In reality, however, not a particle of water has been destroyed. It has merely changed its state. The heat has altered it from the state of liquid water into that of gaseous water, vapour or steam.

* Try the same experiment with a tea-kettle instead of a saucepan, but only put a little water in the teakettle, and shut the lid well down. Then, as soon as the water begins to boil, the steam will shoot out of the spout in a jet; and this will go on as long as any water remains in the kettle.

The steam, as it comes out of the spout, is so hot that it will scald you if you put your finger in it. But you may satisfy yourself that it is very hot, without scalding your fingers, by holding a stick of sealing-wax in it. The wax will soften, just as if you held it before the fire. Moreover, if you look through the steam, just where it leaves the spout, you will see that it is quite transparent; it is only at some little distance from the spout that it loses its transparency, changes into a white opaque cloud, and rapidly vanishes in the air. 


\section{The taking away of Heat from Steam} causes the Steam to change into Hot Water.

Now take a cold spoon, or a cold plate, and hold it against the jet of steam, for a moment : or two. When you take it away, you will find that it is quite wet, being covered with drops of warm water, and, moreover, the cold spoon, or plate, has become warm. And if you fit a long cold metal pipe to the nozzle of the tea-kettle, you will find that no steam at all issues from the end of the pipe, but only water, while the pipe becomes warmed.

Thus the heat passes from the fire into the saucepan, or kettle, and thence to the water which they contain; the water gets hotter and hotter, and, when it has taken in a certain quantity of heat, it becomes steam; or yapour of water. When the steam comes against the cold plate, or passes through the cold pipe, it gives up the heat it has taken in to the plate, or the metal of the pipe. They carry off the heat which kept the water in the condition of a vapour, and so it passes back into the condition of liquid.

Thus steam and water are two conditions of the same thing, water; they are effects of the quantity of heat which the water has taken in.

\section{When Water is changed into Steam,} its Volume becomes about I,700 times greater than it was at first.

If you could measure and weigh the water in your kettle to begin with, and then measure and weigh all the steam into which the heat of the fire changes it, you would find that the bulk of the steam was nearly $r, 700$ times as great as the bulk of the water, though 
the weight of the steam would be exactly the same as that of the water. If you had a small square cup like a die, the inside measure of which was exactly one inch each way, it would hold one cubic inch of water. If this cup full of water were heated till all the water was turned into steam, the steam would nearly occupy a cubic foot; since there are 1,728 cubic inches in a cubic foot. A cubic inch of water weighs $252 \frac{1}{2}$ grains, and the steam into which it is converted has just the same weight. Thus we may say that steam is water expanded by heat into a vapour which is of 1,700 times less specific gravity than water. On the other hand, a pint of steam allowed to cool, becomes converted into a quantity of water, which measures only $\frac{1}{1700}$ th of a pint, though it weighs just as much as the whole pint of steam did. The steam, therefore, is condensed to a $\frac{1}{170} \sigma^{\text {th }}$ of its volume of water.

The power with which water expands when it is converted into steam is very great. If you were to stop up the nozzle of the tea-kettle; the steam, inside the kettle, in trying to expand, would burst open the lid; and if you were to fasten down the lid, it would pretty soon burst the kettle itself. You sometimes hear of the strong boilers of steam-engines being burst in this way.

\section{Gases or Elastic Fluids. Air.}

Here is a glass flask with a long neck and an open mouth. If we pour water in at the mouth until it rises to the lip we say that the flask is full of water. If we now pour the water out we say that the flask is empty. But is it empty? Press the flask mouth 
downwards into a glass jar full of water. If the flask were empty there would be no reason why the water should not enter the neck of the flask and stand at the same height inside the neck as it does outside. If you take an "empty" glass tube open at each end and press it down into the water, the water inside and the water outside will stand at the same level. But if you put your finger on the upper end of the tube so as to convert it into a closed vessel, the water will enter the lower end only a little way. So with the flask, the water enters the neck only a little way. Hence there is something inside the "empty" tube and in the "empty" flask; something which is material, because it occupies space and offers resistance. In fact the flask is full of that form of matter which is termed air, a thick coat of which surrounds the earth as the atmosphere. Air has weight, as you -will learn more fully by and by; and that air in motion can transfer that motion to other bodies you are taught by the effects of the winds, which are merely air in motion.

Air therefore has all the characters of a material substance. Moreover it is a fluid, for it fits itself exactly to the shape of any vessel which contains it ; its parts are very easily moved, or we should feel its resistance every time we move a limb; that it "flows" is seen in every breeze and every time you use a pair of bellows, when the air is driven in a stream out of the nozzle; and it presses on all sides anything contained in it.

But though air is a fluid it is not a liquid. In the first place it is very compressible. We saw that the water entered a little way into the tube or the neck of 
the flask in the preceding experiment. The reason of this is that the water compresses the air into a smaller volume. A bag full of air, such as a common air-cushion, can be squeezed till the air in its interior occupies, a much smaller volume; and, if you treat a syringe full of air in the same way as the syringe full of water was treated, you will find, if the piston fits well, that it can be driven down some distance and then springs back again. Air in fact is not only a compressible, but it is an elastic fluid or gas. Heat expands air just as it expands water, but the expansion of air for the same degree of heat is much greater.

\section{Steam is an Elastic Fluid or Gas.}

In all the properties which have been mentioned water in the form of steam is an elastic fluid or gas like air:-

- If a little water is placed in the flask mentioned in the preceding section all the "empty" part of the space will contain air. If the flask is now made hot the water will at length boil; bubbles of steam forming in the water and breaking at its surface. By degrees; the aair, which at first lay above the water, will be driven out; and, if the whole flask is kept hot; the "empty" part of it will be full of the gaseous water, which is transparent and colourless like air. The steam flows out of the mouth of the flask still a clear and colourless gas; but it soon cools and becomes condensed as a cloud of small particles of fluid water.

'Steam is lighter than air, and hence it rises in the air; just as bodies which are lighter than water rise in water. 


\section{Gases and Vapours.}

Air is as much a gas in the coldest winter as it is in the hottest summer. But air can be liquefied by exposing it to a-very-low temperature, while, at the same time, it is subjected to an extremely great pressure. Thus, the difference between gases like air, which are condensed with extreme difficulty, and gases like steam, which are condensed easily, is only one of degree. Nevertheless there is a certain convenience in distinguishing those "gases, which, like steam, are easily condensed as vapours. In what we ordinarily call steam, all the water of which it is composed remains gaseous only at and above the temperature of boiling -water $\left(22^{\circ}\right.$ Fahrenheit). Cooled ever so little below this point, most of it becomes condensed into hot liquid water. "However, it must be recollected that though that particular form! of gaseous water which we call steam exists only at and above the temperature of boiling water, yet water is capable of existing in the gaseous state down to the freezingpoint.

Suppose that when our boiling flask contained nothing but water and steam, the mouth were stopped and the lamp renoved. Then, so long as the temperature of the whole remained at that of boiling water, every cubic inch of steam above the water in the flask would weigh about $\frac{1}{7}$ th of a grain, since 100 cubic inches weigh about 15 grains. Suppose the capacity of the flask, exclusively of the fluid water in it, to be roo cubic inches. Then, to begin with, the gaseous water which it contains. will weigh I 5 grains. If the flask is now allowed to cool, more and more of the gaseous water condenses into the 
fluid state; but, even down to the freezing-point, some water will remain in the gaseous state and will fill that part of the flask which is unoccupied by the fluid water. At blood-heat $\left(9^{\circ}\right)$ the gaseous water weighs only about a grain, though it still occupies roo cubic inches; at the ordinary temperature of the air it weighs not more than $\frac{1}{3}$ rd of a grain; while, at the freezing-point, its weight is only $\frac{1}{8}$ th of a grain. But inasmuch as there is less and less actual weight of water in the same volume of gaseoús water as the temperature falls, it follows that the density, or specific gravity, of the gaseous water must be less the lower the temperature. Moreover, while, at the boiling-point, gaseous water or steain resists compression with exactly the same force as air does, the lower the temperature the more easily compressible is the gaseous water.

Suppose an elastic bag were to be tied on to the nozzle of a kettle full of boiling water. If the bag were kept as hot as the boiling water it would become fully distended, and maintain its shape in spite of the pressure of the air upon all sides of it. If the bag were taken away it would retain its shape so long as it was kept as hot as boiling water; but, if it were allowed to cool, it would gradually become flattened by the outside air squeezing up the less and less resisting gaseous water of the lower temperatures. Hence, when the stopped flask has been allowed to cool, the air rushes in with great violence if it is opened.

\section{The Evaporation of Water at ordinary Temperatures.}

If some water is poured into a saucer and is 
allowed to stand even in a cool room or in the open air, you know that it sooner or later disappears. Wet clothes hung on a line soon dry-that is to say, the water clinging to them disappears or evaporates. The disappearance of the water under these circumstances results from the property just mentioned. In fact, it becomes gaseous water of the density appropriate to the temperature, and as such mixes with the air as any other gas would do. And as the sea, lakes, and rivers, are constantly giving off gaseous water into the air in proportion to the temperature, it is not wonderful that the atmosphere always contains gaseous water.

Air is said to be moist when the weight of water in a given quantity, say 100 cubic inches, is as much, or nearly as much, as can exist in the state of gas at the temperature. Under these circumstances, if the temperature is lowered even a very little, some of the gaseous water is converted into liquid water. We see this in hot moist weather, when the outside of a tumbler of fresh drawn cold spring water immediately becomes bedewed. The gaseous water in immediate contact with the tumbler, in fact, is cooled down below the point at which it can all exist as gas, and the superfluity is deposited as dew. In such days wet clothes do not dry well, because there is, already, nearly as much gaseous water in the atmosphere as the amount of heat marked by the thermometer can maintain in that state.

\section{When Hot Water is Cooled, it Con-} tracts to begin with, but after a time Expands.

We have now seen what a wonderful change is 
brought about by heating water. At first, it expands gradually and slightly; but, when it reaches the boiling-point, it suddenly expands enormously, and is no longer a liquid, but a gas.

On the other hand, if warm-water is allowed to cool, it gradually contracts till it reaches the ordinary temperature of the air in mild weather; but, if the weather is very cold; or if the water is cooled artificially, it goes on contracting only down to a certain temperature $\left(39^{\circ}\right)$, and then begins to expand again. In this peculiarity water is unlike all other bodies which are fluid at ordinary temperatures. Hence the temperature of $39^{\circ}$ is that at which pure water has its greatest density or specific gravity; and water at this temperature is heavier, bulk for bulk, than the same water at any other temperature. Therefore if water at the top of a vessel is cooled down to this temperature, it falls to the bottom, and if the water at the bottom of a vessel is cooled below this temperature it rises to the top.

40. Water cooled still further becomes the transparent brittle solid Ice,

Oúr tumbler of water, if put out of doors on a cold winter's night, would gradually cool until at assumed a temperature of $39^{\circ}$ throughout. Cooling below this temperature, the water so cooled, would gradually. accumulate at the surface by reason of its less density, and its temperature would fall till the thermometer placed in it marked $32^{\circ}$. As soon as this upper water cooled ever so little below $3^{\circ}$, a film, like glass, would form on its surface by the conversion of the coldest fluid water into solid water, or ice. And if all the 
water cooled down to the same flegree it would all gradually change into the same kind of substance.

In this condition water is solid. - It occupies space, offers resistance, has weight, and tránsmits motion cas the water did, but if you shake it out of the tumbler in a cold place it retains its ' form without the least change. If you press it, it proves to be exceedingly hard and unyielding; and, if the pressure is increased, it becomes crushed and breaks like glass. It may thus be crushed to powder, and the ice powder can be formed into heaps as if it were sand.

Just as any quantity of steam has exactly the same weight as the water which was converted into it by heat; so the ice has exactly the same weight as the water which has been converted into it by taking away heat.

\section{I. Ice has less Specific Gravity than the} Water from which it was formed.

But though the ice in the tumbler lhas the: same weight as the water had, it has not the same volume. The expansion which began at $39^{\circ}$ goes on, and when water passes into the solid state its volume is about $\frac{1}{11}$ th greater than it was at" $39^{\circ}$. Taking water at this temperature as I.o, ice has a specific gravity of $\sigma^{\circ} .16$.

But although water in freezing expands only to this small amount, it resembles steam in the tremendous force with which it expands. If you fill a hollow iron shell quite full of water, screw down the opening tight; and then put it in a cold place where the water may |freeze; the water as 'it freezes will burst the iron walls of the shell. You know that when the winter is severe, the pipes by which water is brought 
to a house often burst. This is because the water in them freezes, and, being unable to get out of the pipe, bursts it, just as you may burst a jacket that is too tight for you by stretching yourself. Among the bare hill-tops, or on the face of cliffs exposed to the weather, the strongest and hardest rocks are every winter split and broken, just as if quarrymen had been at work at them. In the summer the rainwater gets into the little cracks and rifts in the stone and lodges there. Then the winter comes with its cold and freezes the water. And the water bursts the rocks asunder just as it bursts our waterpipes.

42. Hoar Frost is the Gaseous Water which exists in the Atmosphere, condensed and converted into Ice Crystals.

In the winter-time you often notice, on a clear sharp night, that the tops of the houses and the trees are covered with a white powder called hoar frost; and, on the windows of the roum when you wake up, you see most beautiful figures, like delicate plants. Take a little of the hoar-frost, or scrape off some of the stuff that makes the window look like ground glass, and you find that it melts in your hand and turns to water. It is in fact ice. And if you look at the figures on the window pane with a magnifying glass you will see that they are made up bits of ice which have a definite shape, and are arranged in a regular pattern. Each of these definitely shaped bits of ice has been formed in the following way. The air in the room is much warmer than that outside, and there is mixed with it nearly as 
much water, derived from the breath and the evaporation of moist surfaces, as can maintain itself in the gaseous state at the temperature. The windowpanes, being thin, are cooled by the outside air, and of course the gaseous water inside the room, when it comes in contact with the cold windowpanes, becomes condensed on them into fine drops of cold water. The panes becoming colder and colder, these minute drops at last freeze, and the water not only becomes solid, but it crystallises; that is to say, the little solid masses take on more or less regular geometrical forms with flat faces, inclined to one another at constant angles, so that they resamble bits of glass cut according to particular fixed patterns. All ice is in fact crystalline, but in ice which has been formed from thick sheets of water, the crystals are so packed together that they cannot be distinguished separately.

43. When Ice is warmed it begins to change back into Water as soon as the Temperature reaches $32^{\circ}$.

A lump of ice brought out of the open air in very cold weather may have a temperature of $30^{\circ}$, or $20^{\circ}$, or lower. If such a lump is brought into a warm room it gradually becomes warmer, but remains unchanged otherwise, until it has risen to $32^{\circ}$. Then it begins to melt, and remains at $32^{\circ}$ as long as it is melting; and the water which proceeds from it is at first also at $32^{\circ}$.

If you were to throw a lump of ice into the middle of a hot fire, so long as a particle of ice remained as such, it would have a temperature of $32^{\circ}$ and no more. This is a fact exactly parallel to that which is observed 
when water is raised to the boiling-point. So long as any of the water remains unconverted into steam it becomes no hotter. Moreover the steam itself is at first at $212^{\circ}$.

44. Ice the solid, Water the liquid, and Steam the gas, are three states of one na: tural object; the Condition of each State being a certain Amount of Heat.

Ice, liquid water, and steam, are three things as unlike as any three things can well be. What do we mean then by saying that they are states of one substance, water?

What we really mean is that if we take a given quantity of water, say a cubic inch, and change it first into ice and then into steam, there is something which remains identically the same through all these changes. This something is, in the first place, the yeight of the material substance. The water weighs $252 \frac{1}{2}$ grains, the ice into which it is converted weighs $252 \frac{1}{2}$ grains, and the steam produced from it weighs $252 \frac{1}{2}$ grains. In the second place, the same force would cause the ice, the water, and the steam, to move with the same rapidity; and, when set in motion, they would produce the same effect upon anything movable against which they struck.

In the third place, when you study chemistry, you will learn that the ice, the steam, and the liquid water, would yield the same weight of the same two gases, oxygen and hydrogen, and nothing else. Every one cubic inch of water, 1,700 cubic inches of steam, and $r_{11}^{1}$ cubic inch of ice, yield $28 \frac{1}{18}$ grains of 
hydrogen, with $224 \frac{8}{18}$ grains of oxygen, and nothing else.: (See \$ 50.)

As there is not the slightest difference in weight between a given quantity of water and the ice, or the steam, into which it may be converted, it is clear that the heat which is added to or taken from the water to give rise to these several states, can possess no weight. If then heat is a material body, it must be devoid of weight-and hence, in former times, heat was called an imponđerable substance. It was thought to be a kind of fluid, called caloric, which had no weight, and which drove the particles of bodies asunder, when it entered them as they were heated, and let them come together as it left and they grew cool.

45. The Phenomena of Heat are the Effects of a rapid Motion of the Particles of Matter.

This much, however, is certain : that heat can be caused by motion. Every boyknows that a metalbutton may be made quite hot by rubbing it. A skilful smith will hammer a piece of iron red hot. The axles of wheels become red hot by rubbing against their bearings, if they are not properly lubricated; and even two pieces of ice may be melted by the heat evolved when they are rubbed together. And there are abundant other reasons, as you-will find when you study physics, for the belief that the sensation we call heat, and all the phenomena which we ascribe to heat, are the effects of the rapid motion of matter.

However, a quiescent body may be made hot without exhibiting the least appearance of motion. The 
surface of the water in a tumbler at $100^{\circ}$ is just as unruffled as that of the same water at $3^{\circ}$. What, then, is meant by saying that heat is a kind of motion, and that the greater the heat in any body the greater the amount of motion in that body?

The answer to this question is that the motion which causes the phenomena of heat, is not a visible motion of the whole mass of the hot body, but a motion of the individual particles of which it is composed. And each particle moves, not straight forward, but backwards and forwards in the same space, so that its motion may be roughly compared to that of a pendulum, or to that of the balance-wheel of a watch. It is in fact a sort of vibratory movement ; each vibration taking place through a very short distance and with extreme rapidity. The sensation of heat is caused by the vibratory movements of the particles of matter, just as sound is so caused. The prongs of a tuningfork which has been struck, certainly vibrate, foi you can see them do so if the note is low. If you now put your ear at one end of a long piece of timber and the handle of the vibrating tuning-fork is placed upon the other end, the vibratory motion of the tuning-fork will be communicated to the particles of the wood and will be loudly heard. All the time the sound is heard the particles of the wood are vibrating. Nevertheless, the wood as a whole does not move, but its particles swing backwards and forwards through such a minute space that their motion is imperceptible.

But what are these particles of matter which by their vibration give rise to the phenomena of heat? 


\section{The Structure of Water.}

We have seen that pure water is perfectly clear and transparent. The naked eye can discern no difference between one part and another. In other words, it has no visible texture or structure. It does not follow that it really possesses none, however, for there are many things which seem to be the same throughout, or homogeneous, which yet show structure if they are examined with a magnifying glass. Thus the surface of a sheet of fine white paper looks perfectly even and smooth to the eye; but a magnifying glass of no great power will show the minute woody fibres of which it is made up; while, under a powerful microscope, the paper looks like a coarse matting.

But if we put a small drop of water on a slide, such as is used for microscopic objects, and cover it over with a thin glass so as to spread it out into a film, perhaps not more than $\frac{1}{10000}$ th of an inch thick, it may be examined with the very highest magnifying powers we can command, and yet it looks as completely homogeneous and shows as little evidence of being made up of separate parts as before. However, this is still no proof that the water is not made up of little parts, or particles, distinctly separated from one another. It may merely mean that the particles are so extremely small that they cannot be distinguished even by microscopes which magnify four or five thousand diameters.

It is certain that solid bodies may be divided into particles so minute that the best microscopes show no trace of them. Common gum-mastic cannot be dissolved by water, but it readily dissolves in strong spirit or alcohol, and mastic varnish is an 
alcoholic solution of gum-mastic. If you add water to mastic varnish, the alcohol takes away the water and the mastic falls out, or precipitates, as a curdy solid composed of very visible whitish particles. But if a drop of the varnish is added to a good deal, say half a pint, of water and well stirred at the same time, the mastic, though it is still precipitated as a solid, is in a state of extremely minute division. No separate solid particles of mastic are visible to the naked eye, but the water assumes a faint milky tinge.

This milkiness arises from the presence of solid particles of mastic diffused through the water; and yet, if the experiment has been properly managed, a drop of the fluid may be spread out as before and examined with the highest magnifying powers, and nothing can be seen of such particles. So far as vision goes it might be a drop of pure water. Now our best microscopes are able to show us anything solid which has a diameter of $\frac{1}{100000}$ th of an inch, quite distinctly; and probably solid opaque particles of much smaller size would make themselves apparent as a turbidity or cloudiness. The particles of mastic must be therefore so much smaller than this that they remain invisible. Hence it follows that if water were made up of separate particles, or droplets, $\frac{1}{1000000}$ th of an inch in diameter, and thus had the structure of a mass of very fine shot, no microscope that has yet been constructed would enable us to see even a trace of that structure." We could not obtain any direct evidence of it. 


\section{Suppositions or Hypotheses; their}

\section{Uses and their Value.}

When our means of observation of any natural fact fail to carry us beyond a certain point, it is perfectly legitimate, and often extremely useful, to make a supposition as to what we should see, if we could carry direct observation a step further. A supposition of this kind is what is called a hypothesis, and the value of any hypothesis depends upon the extent to which reasoning upon the assumption that it is true, enables us to explain or account for the phenomena with which it is concerned.

Thus, if a person is standing close behind you, and you suddenly feel a blow on your back, you have no direct evidence of the cause of the blow; and if you two were alone, you could not possibly obtain any; but you immediately suppose that this person has struck you. Now that is a hypothesis, and it is a legitimate hypothesis, first, because it explains the fact; and secondly, because no other explanation is probable; probable meaning in accordance with the ordinary course of nature. If your companion declared that you fancied you felt a blow, or that some invisible spirit struck you, you would probably decline to accept his explanation of the fact. You would say that both the hypotheses by which he professed to explain the phenomenon were extremely improbable ; or in other words, that in the ordinary course of nature fancies of this kind do not occur, nor spirits strike blows. In fact, his hypotheses would be illegitimate, and yours would be legitimate; and, in all probavility, you would act upon your own. In daily life, nine-tenths of our actions are based 
upon suppositions or hypotheses, and our success or failure in practical affairs depends upon the legitimacy of these hypotheses. You believe a man on the hypothesis that he is always truthful; you give him pecuniary credit on the hypothesis that he is solvent.

Thus, everybody invents, and, indeed, is compelled to invent, hypotheses in order to account for phenomena of the cause of which he has no direct evidence ; and they are just as legitimate and necessary in science as in common life. Only the scientific reasoner must be careful to remember that which is sometimes forgotten in daily life, that a hypothesis must be regarded as a means and not as an end; that we may cherish it so long as it helps us to explain the order of nature; but that we are bound to throw. it away without hesitation as soon as it is shown to be inconsistent with any part of that order.

48. The Hypothesis that Water is composed of Separate Particles (Molecules).

It has been pointed out that we cannot see, and indeed that there is not much hope of our ever being able to see, the separate particles of water, even if water is composed of such particles. But it is perfectly legitimate to suppose that water is made up of such particles, if that hypothesis will enable us to explain the properties of water.

Let us suppose then that any portion of fluid water is really composed of a prodigious number of particles less (and probably much less) than a millionth of an inch in diameter. We may call these particles molecules. ${ }^{1}$

1 Diminutive of moles, a mass. 
We are justified, in accordance with the general properties of matter (\$ 18 ), in supposing that these molecules tend to approach one another. But the fact that water is slightly compressible justifies the supposition that its molecules are not in actual contact, but that they are separated by interspaces, just as the motes in the air of a dusty room are so separated.

What is it that keeps the molecules apart? We have seen that great mechanical pressure brings them but slightly nearer to one another; hence there is an equivalent resistance of some kind which keeps them apart. This resistance must have the same origin as the sensation which we know as heat, for it has been seen that diminution of heat diminishes the bulk of water ; that is, allows the molecules to come closer together; that is, diminishes their tendency to keep asunder. Increase of heat, on the other hand, increases the volume of water; that is to say, drives the molceules further apart, or increases their tendency to keep asunder.

Suppose we call the cause of the tendency of the molecules of water to come together an attractive force; and the cause of their keeping apart, which manifests itself to us as the sensation of heat and is, as we have seen, in all probability, a rapid vibratory or whirling motion of the molecules; a repulsive force ; then, in the liquid state, these forces are so adjusted that the molecules are quite free to move, and yet hold together.

By adding heat the repulsive force is increased, until the molecules are about twelve times fas ar apart as they were in each direction; while the attractive 
force is overcome, and the molecules fly off in all directions as soon as they are unconfined. On the other hand, by taking heat away, the repulsive force is diminished, until the molecules become inseparable and the water assumes the solid form.

It is probable that the expansion of fluid water, at a temperature below $39^{\circ}$, depends upon the molecules taking up a peculiar arrangement as they approach one another. If sixteen men are formed into a column, four deep, and each man a foot from the other, the same men may stand closer together and yet form a hollow square, which occupies a larger space. That the molecules of water do take up a particular order in assuming the solid condition, is shown by the crystalline form of ice. Each crystal of hoarfrost owes its shape to the arrangement of its molecules, according to a definite geometrical pattern.

Thus the hypothesis that water is composed of separate molecules, is useful, for it helps us to some extent to explain the properties of water. And, when you stuay physics and learn the laws of motion, you will find that there is no end to the number of the truths established by observation and experiment, which can be explained by this hypothesis. Hence it may fairly be adopted and employed as a means of picturing to ourselves the order of nature, so long as no facts are discovered which are inconsistent with it.

\section{All Matter is probably made up either of Molecules or of Atoms.}

The same reasons which lead to the adoption of the hypothesis that water is composed of separate 
particles justify its extension to all forms of matter whatever.

The metal mercury or quicksilver, for instance, may be supposed to be made up of distinct particles of mercury of extreme minuteness, and according to the temperature, these associate themselves in the solid (frozen mercury), liquid (ordinary quicksilver), or gaseous form (vapour of mercury). To whatever treatment pure mercury may be subjected, we cannot get anything but mercury out of it. The particles of mercury have never been broken up. Hence they are generally termed atoms, or particles that cannot be divided; and mercury is said to be an element, or a substance which is not compounded of any other substances.

Here is a case in which it is very useful to distinguish between fact and hypothesis. The matter of fact is that, up to the present time, no one has been able to get out of pure mercury anything but pure mercury. The statement that mercury is a simple substance, and therefore never can be broken up into any other substances, is a hypothesis which future observation and experiment may or may not confirm.

A hundred and fifty years ago it was universally believed that water was as much an element as mercury. But water is now well known to be a compound. In fact, as has already been said, the particles of water may be very readily broken up or decomposed (in what way, you will learn when you study chemistry) into two totally distinct substances, oxygen and hydrogen, which are gaseous at all known temperatures, though by combining vast pressure with extreme cold they have recently been 
liquefied. Each of these gases, according to our lyypothesis, consists of particles, and since these can by no known means be further broken up, they are considered to be atoms like those of mercury.

Nine parts by weight of pure water always yield eight of oxygen and one of hydrogen. The hypothetical particle, or molecule of water, therefore, must be composed of atoms of oxygen and hydrogen having this relative weight; and chemists have grounds for believing that one atom of oxygen and two atoms of hydrogen exist in each molecule of water. If this be so, the structure of water must be more complicated than we thought at first; and cach particle of water (the molecule) must be a system composed of three separate atoms.

50. Elementary Bodies are neither destroyed nor is their Quantity increased in Nature.

It has been seen that when a cubic inch of water is dissipated by heat, it is not destroyed, but that it merely changes its form from the fluid to the gaseous state, while its weight remains unaltered. If the same cubic inch of water is decomposed into oxygen and hydrogen gases, the water is indeed destroyed, but the matter of which it consisted remains unchanged in weight. If the water weighed $25^{2} 5$ grains, the oxygen gas will weigh $224^{\circ} 45$ grains, and the hydrogen gas will weigh 28.05 grains. And nothing that man has been able to do has affected the weight of a given quantity of either of these gases. So far as we know, elementary bodies retain their weight under all 
circumstances, and can be traced by it whatever shape they may take. If this is true it follows that, in the order of nature, matter is indestructible: the quantity of it neither increases nor diminishes.

Hence it follows that natural things and artificial things resemble one another in one respect. It is true of both that the matter of which they are composed is never destroyed and never increased; and therefore the order of events in nature as much consists in the joining together and putting apart of natural bodies by natural agencies, as the order of events in the artificial world consists in the joining together and the putting apart of natural bodies by human agencies.

\section{Simple Mixture.}

In order to learn the manner in which water may be broken up into its elements or decomposed, you must turn to the Primer on Chemistry. But as a preliminary to the study of that science, it may be useful to consider some simple cases of composition and decomposition which are exemplified by water.

If half a pint of water, coloured by putting a little ink into it, is added to the same quantity of clean water, the two will readily mingle; the total quantity of water will be a pint; and its colour will be just half as dark as that of the coloured half-pint. This is a case of simple mixture. The volume of the mixture equals the sum of the volumes of the things mixed, and there is no change in the properties of these things. So when water evaporates, the gaseous water or vapour mixes with the air in the same way, the molecules of the one body dispersing themselves between 
the molecules of the other until there is the same proportion of each everywhere. In like manner, sand and sugar may be (and unfortunately often are) mixed, without any change in the properties of either, or in the space which they primitively occupied.

On the other hand, oil and water will not mix, however much you may stir the two together; and the oil, being the lighter, rises to the top as soon as the fluid is quiet. Nor will quicksilver and water mix, but the quicksilver, being very much heavier than the water, rushes to the bottom of the vessel into which the two are put. Neither will sand nor iron filings mix with water; as heavier bodies, they also sink to the bottom. Nor does powdered ice, though it is water in another shape, mix with ice cold water; as a lighter body, it floats at the top.

\section{Mixture followed by Increase of Den- sity; Alcohol and Water.}

Strong spirit, or alcohol, is a clear transparent fluid which looks like water, but is a very different substance. For example, it boils at a much lower temperature, it burns with a blue flame, it has intoxicating properties, and, like oil, it is very much lighter than water. Hence if coloured spirit is poured gently upon the surface of water the spirit rests upon the water. Suppose, now, that we take a tall measure graduated into ten equal parts. Fill the lower five with water, and then, very gently, pour in the strongest alcohol, coloured in some way, until the tenth mark is reached. We shall have five volumes of water below, and an equal quantity, or five volumes, of coloured alcohol above. Where the two are in contact, the colour will be 
diffused into the water for a short distance, but not far, showing that only a slight mixture is taking place. This, however, is not because the two fluids mingle with difficulty ; for, with slight stirring; they mix completely, and you have a fluid the colour of which is about half as intense as that of the alcohol, and many of the other properties of which are intermediate between those of pure alcohol and those of pure water.

Thus far, nothing further than simple mixture, as when coloured water was added to pure water, seems to have occurred; but, in reality, something more has happened. In the first place, the mixture is a good deal warmer than either of its components; that is to say, heat has been generated. In the second place, if you measure the volume of the whole fluid after it has cooled, it no longer stands at the mark ten but distinctly lower, or about nine and threequarters. As the volume of the mixture is less than the sum of the volumes of its two components, it follows that the density of the mixture must be greater than a density midway between that of the water and that of the alcohol. In other words, the molecules in the mixture do not occupy the same space as they did when they were separate. The result is the same as if the ten volumes had been compressed until they occupied only nine and three-quarters; so that the effect is a contraction similar to that which would be brought about by taking away heat from the mixture. In fact, as we have seen, the mixture gives out a quantity of heat.

There is another respect in which the mixture is unlike both its constituents. It both boils and 
freezes at a much lower temperature than water does, and at a higher temperature than alcohol does. In fact pure alcohol has not yet been frozen. If the molecules of the alcohol were merely diffused among those of the water as water is diffused through wet sand, they ought to pass into the gaseous state at the same temperature as that at which alcohol boils; and it would then be very easy to separate alcohol from water by distillation. But the fact is not so; alcohol cannot be obtained free from water by distillation unless something which holds water very strongly, such as quicklime, is added, so as to keep all the water back when the fluid is heated.

Thus alcohol and water, mingled together, give rise to a fluid which is not a mere mixture, the properties of which are known if we know the properties of its components ; it is, in strictness, a new body, in which the molecules of the water and those of the alcohol affect one another to a certain extent, and modify the pre-existing properties of each.

This effect of different bodies upon one another becomes much more manifest when water is brought into contact with certain solids.

\section{Solution: Water Dissolves Salt.}

If a spoonful of salt is put into a tumbler of cold water and the water is stirred, the salt swiftly vanishes from view ; and, after a time, so far as our sense of vision goes, the water appears to be just what it was before. But if the water in the tumbler at first weighed five ounces and the salt weighed two ounces, the water in the tumbler will now weigh seven ounces; the water will now taste salt, the salt is said to be 
dissolved, and the solution is called brine. Moreover, the solution is said to be saturated, for if you put more salt in it will remain unchanged. Water, in fact, will dissolve two-fifths of its weight of salt, and no more. If the brine thus formed is put into a wide dish, so that the water may evaporate; or if it is heated and the water boiled away; as fast as the water diminishes, a quantity of salt, equal to two-fifths of the water which is converted into steam, returns to the solid state and falls to the bottom of the vessel. And when all the water is driven off, the salt which remains will have exactly the weight, and all the other properties which it had before it was dissolved by the water.

Thus, contact with water has had a very singular effect upon the salt. It appears to have changed one of the properties of the salt, namely, its solidity, but to have left all the rest unaltered. We saw just now that powdered ice does not mix with ice-cold water, but that the fragments of ice remain solid. The moment, however, that the temperature rises, the cohesion, or sticking together of the molecules, which is the characteristic of the solid state, comes to an end; they become loose and free to move, and they mingle with the surrounding water. Or we may say that the ties which held the molecules of the solid together are dissolved, so that the solid water becomes fluid.

The resemblance of this process to the dissolving of salt in water is so obvious that, in common language, it is often said that a lump of salt or of sugar melts away in water; but if you try to make salt fluid by heat, you will have to expose it to a very high 
temperature, so that the conversion of salt from the solid state into the liquid state by solution in cold water is obviously a very different process from liquefaction by heat. Nevertheless the result is the same so far as the condition of the salt is concerned. The cohesion between its molecules is destroyed, and they distribute themselves evenly among the molecules of the water, just as the molecules of steam distribute themselves among the molecules of air. And, when you study chemistry, you will learn how it may be proved that the smallest drop of the solution of salt contains exactly the same proportion of salt as the whole does.

If brine is allowed to evaporate slowly, the molecules of the salt arrange themselves, as the water leaves them, in beautifully regular cubical crystals. You may see them form easily enough if you watch a drop of brine gradually dry up under a microscope. The salt crystals contain nothing but salt. If they are heated till they become red-hot they pass into the fluid state; and when still further heated, the fluid salt becomes a vapour or gas and, as such, flies off into the air, or volatilizes.

Thus we see that when salt and water are brought into contact, the salt undergoes a certain amount of change, while the water does not remain wholly unchanged. For brine no longer boils at $22^{\circ}$ but requires a considerably higher temperature. The salt, as it were, holds the water back and prevents it from assuming the gaseous state under the same conditions as if it were pure, just as, in the previous case, the water held the alcohol back; or we may say that the force of heat which drives the molecules of liquid water apart, when 
steam is formed, has a greater resistance to overcome when salt is dissolved in the water. And just as the presence of alcohol lowers the freezing point of the water with which it is mixed, so does the presence of salt lower the freezing point of water. Sea water, which is a weak brine, begins to freeze at about $27^{\circ}$; and the ice which is formed is quite pure, while the remainder of the sea water becomes richer in salt.

If we mean by attraction that which opposes any force which tends to separate bodies, then we may say that the molecules of salt and those of water attract one another. And such attraction between molecules of matter of different kinds is called chemical attraction.

54. Quicklime and Water: Plaster of Paris and Water: Combination.

Quicklime is a substance obtained by heating chalk or limestone to redness. When pure, it is a white hard solid which can be made to pass into the liquid and gaseous states only at enormously high temperatures. If a lump of fresh quicklime is placed in a saucer and about one-third of its weight of water poured upon it, there will be a great turmoil, heat will be evolved, the water will disappear, and the lime will crumble down into a soft white powder. This operation is what bricklayers call slaking lime. And if no more water has been added than the proportion mentioned, the pure white powder which results will be solid and dry, the water having to all appearance, vanished.

In the solution of salt we saw a solid become fluid under the influence of water; in the slaking of lime the fluid water enters into the structure of a solid. 
If more water is added, this solid dissolves or becomes liquid, as the salt did, and the solution is called limewater. By carefully-managed evaporation of the water the lime may be recovered in the form of crystals, just as the salt was recovered. But there is this difference, that the salt crystals contain no water, while the lime crystals not only contain water, but contain exactly the same proportion as exists in slaked lime, that is to say, 18 parts water to $5^{6}$ parts lime.

The water thus bound up with the lime into a new solid holds on so firmly to the lime that it requires a red heat to separate the two. The lime and the water are said to be chemically combined; and as the proportion of lime and water in slaked lime, or lime crystals, is always the same, they are said to be combined in definite proportions ; and the slaked lime receives the special name of hydrate of lime.

Gypsum or Plaster of Paris is a dry white powder. If mixed with a little water it does not slake after the fashion of quick lime, but the mixture soon sets or becomes hard; and, at the same time, the greater part of the water disappears. In fact, it has combined with the plaster of Paris and forms part of another hydrate, in which, when the superfluous moisture dries, not a trace of water is to be seen. It is this property which is taken advantage of when plaster of Paris is used for making casts and moulds. The fluid plaster is poured over and round the body to be cast ; as a fluid, it applies itself conveniently to all the inequalities of its surface; and, when it sets, it retains the shape which it has thus acquired. Set plaster of Paris may be perfectly dry; but it nevertheless contains 
between $\frac{1}{\gamma}$ and $\frac{1}{8}$ of its weight of water, fixed and forming an integral part of the solid hydrate. And if the set plaster is strongly heated, the combined water is driven off and it returns to its original state.

Gypsum is found abundantly in nature, in the shape of beautiful transparent crystals which are called selenite. These crystals have the same composition as set plaster, that is to say, they are hydrates. A thin flake of such a crystal viewed with the highest powers of the microscope appears perfectly homogeneous. Nevertheless, there is good reason for the conclusion that it consists of molecules of water and molecules of gypsum which hold together so strongly that they form a hard brittle glassy solid. Moreover, the molecules of the hydrate itself hold together more strongly in some directions than in others. It is very easy to split the crystals lengthwise; while much more force is needed to cut them crosswise and then they do not split, but break.

Glauber's salts and Epsom salts are other examples of solids which dissolve in water and separate in the crystalline form as the water evaporates; and which, like lime and gypsum, combine with a definite proportion of water to form crystalline compounds. In fact, each of these glassy brittle solids contains more than half its weight of water.

Thus we see that two bodies, of which water is one, may combine together to give rise to something different from either. And we are thus led to the science of chemistry, which tells us exactly how bodies combine, what comes of their combination, and how compounds may be separated into their constituents. 
55. Mineral bodies may take on definite shapes and grow, or increase in size, by the addition of like parts.

Water and all the other natural bodies which have hitherto been mentioned, are what are called mineral bodies, although, in common use, the term mineral is usually restricted to ores and metals. Now we have repeatedly had occasion to remark that, under certain circumstances, not only water, but many other mineral bodies, assume regular shapes. The most familiar example is, that of the beautiful imitation of leaves and foliage which is presented by the ice which forms on a window in winter. But we have also seen that common salt, lime, gypsum, Glauber's salts and Epsom salts, also assume the crystalline form as they or their compounds with water, are deposited from their solutions. And if a drop of solution of Glauber's salts or of Saltpetre, is allowed to evaporate under the microscope, a wonderful spectacle will be presented. As the salt assumes the solid state, the crystals suddenly appear in the field of view as needles and plates disposed in beautiful patterns, which rival those of hoar frost, though they are quite different from them. In fact, as you will learn if you study crystallography, every crystallizable substance has its proper crystalline forms and never departs from certain strictly related geometrical figures.

A crystal of any of these substances will grow if placed under proper conditions. Thus, if a crystal of common salt is hung by a thread in a saturated solution of salt, which is exposed to the air, so as to aliow the water to evaporate slowly, the molecules of the salt which is left behind and can no longer be held 
in solution, deposit themselves on the crystal in regular order and increase its size without changing its form. And, in this way, the small crystal may grow to a great size. 'The large crystals of sugar candy, which consist of sugar and water deposited from a strong syrup or saturated solution of sugar, grow in the same fashion, upon threads suspended in the evaporating syrup. In this mode of growth you will observe that the enlargement is effected by addition to the outside of the growing body ; and moreover the matter which is added, namely, the salt or the sugar, already exists as salt in the brine or as sugar in the syrup.

\section{B. LIVING BODIES.}

56. The Wheat Plant and the substances of which it is composed.

Every one has seen a cornfield. It you pluck up one of the innumerable wheat plants which are fixed in the soil of the field, about harvest time, you will find that it consists of a stem which ends in a root at one end and an ear at the other, and that blades or leaves are attached to the sides of the stem. The ear contains a multitude of oval grains which are the seeds of the wheat plant. You know that when these seeds are cleared from the husk or bran in which they are enveloped, they are ground into fine powder in mills, and that this powder is the flour of which bread is made. If a handful of flour mixed with a little cold water is tied up in a coarse cloth bag, and the bag is then put into a large vessel 
of water and well kneaded with the hands, it will become pasty, while the water will become white. If this water is poured away into another vessel, and the kneading process continued with some fresh water, the same thing will happen. But if the operation is repeated the paste will become more and more sticky, while the water will be rendered less and less white, and at last will remain colourless. The sticky substance which is thus obtained by itself is called gluten; in commerce it is the substance known as maccaroni.

If the water in which the flour has thus been washed is allowed to stand for a few hours, a white sediment will be found at the bottom of the vessel, while the fluid above will be clear and may be poured off. This white sediment consists of minute grains of starch, each of which, examined with the microscope, will be found to have a concentrically laminated structure. If the fluid from which the starch was deposited is now boiled it will become turbid, just as white of egg diluted with water does when it is boiled, and eventually a whitish lumpy substance will collect at the bottom of the vessel. This substance is called vegetable albumin.

Besides the albumin, the gluten, and the starch, other substances about which this rough method of analysis gives us no information, are contained in the wheat grain. For example, there is woody matter or cellulose, and a certain quantity of sugar and fat. It would be possible to obtain a substance similar to albumin, starch, saccharine and fatty matters, and cellulose, by treating the stem, leaves, and root in a similar fashion, but the cellulose would be in far 
larger proportion. Straw, in fact, which consists of the dry stem and leaves of the wheat plant, is almost wholly made up of cellulose. Besides this, however, it contains a certain proportion of mineral bodies, among them, pure flint or silica; and, if you should ever see a wheat rick burnt, you will find more or less of this silica, in a glassy condition, in the embers. In the living plant, all these bodies are combined with a large proportion of water, or are dissolved, or suspended in that fluid. The relative quantity of water is much greater in the stem and leaves than in the seed.

57. The Common Fowl and the Substances of which it is Composed.

Everybody has seen a common fowl. It is an active creature which runs about and sometimes flies. It has a body covered with feathers, provided with two wings and two legs, and ending at one end in a neck terminated by a head with a beak, between the two parts of which the mouth is placed. The hen lays eggs, each of which is inclosed in a hard shell. If you break an egg the contents flow out and are seen to consist of the colourless glairy "white" and the yellow "yolk," If the white is collected by itself in water and then heated it becomes turbid, forming a white solid, very similar to the vegetable albumin, which is called animal albumin.

If the yolk is beaten up with water, no starch nor cellulose is obtained from it, but there will be plenty of fatty and some saccharine matter, besides substances more or less similar to albumin and gluten.

The feathers of the fowl are chiefly composed of horn; if they are stripped off and the body is 
boiled for a long time, the water will be found to contain a quantity of gelatin, which sets into a jelly as it cools; and the body will fall to pieces, the bones and the flesh separating from one another. The bones consist almost entirely of a substance which yields gelatin when it is boiled in water, impregnated with a large quantity of salts of lime, just as the wood of the wheat stem is impregnated with silica. The flesh, on the other hand, will contain albumin, and some other substances which are very similar to albumin, termed fibrin and syntonin.

In the living bird, all these bodies are united with a great quantity of water, or dissolved, or suspended in water; and it must be remembered that there are sundry other constituents of the fowl's body and of the egg, which are left unmentioned, as of no present importance.

58. Certain Constituents of the Body are very similar in the Wheat Plant and in the Fowl.

The wheat plant contains neither horn, nor gelatin, and the fowl contains neither starch, nor cellulose ; but the albumin of the plant is very similar to that of the animal, and the fibrin and syntonin of the animal are bodies closely allied to both albumin and gluten.

That there is a close likeness between all these bodies is obvious from the fact that when any of them is strongly heated, or allowed to putrefy, it gives off the same sort of disagreeable smell; and careful chemical analysis has shown that they are, in fact, all composed of the elements Carbon, Hydrogen, Oxygen, and Nitrogen, combined in very nearly 
the same proportions. Indeed, charcoal, which is impure carbon, might be obtained by strongly heating either a handful of corn, or a piece of fowl's flesh, in a vessel from which the air is excluded so as to keep the corn or the flesh from burning. And if the vessel were a still, so that the products of this destructive distillation, as it is called, could be condensed and collected, we should find water and ammonia, in some shape or other, in the receiver. Now ammonia is a compound of the elementary bodies, nitrogen and hydrogen; therefore $(\S 50)$ both nitrogen and hydrogen must have been contained in the bodies from which it is derived.

It is certain, then, that very similar nitrogenous compounds form a large part of the bodies of both the wheat plant and the fowl, and these bodies are called proteids.

59. Proteid Substances are met with in Nature only in Animals and Plants; and Animals and Plants always contain Proteids.

It is a very remarkable fact that not only are such substances as albumin, gluten, fibrin and syntonin, known exclusively as products of animal and vegetable bodies; but that every animal and every plant, at all periods of its existence, contains one or other of them, though, in other respects, the composition of living bodies may vary indefinitely. Thus, some plants contain neither starch nor cellulose, while these substances are found in some animals; while many animals contain no horny matter and no gelatin-yielding substance. So that the matter which appears to be the essential 
foundation of both the animal and the plant is the proteid united with water; though it is probable that, in all animals and plants, these are associated with more or less fatty and amyloid (or starchy and saccharine') substances, and with very small quantities of certain mineral bodies, of which the most important appecr to be phosphorus, iron, lime, and potash.

Thus there is a substance composed of water + proteids + fat + amyloids + mineral matters which is found in all animals and plants; and, when these are alive, this substance is termed protoplasm.

\section{6o. What is meant by the word Living?}

The wheat plant in the field is said to be a living thing; the fowl running about the farmyard is also said to be a living thing. If the plant is plucked up, and if the fowl is knocked on the head, they soon die and become dead things. Both the fowl and the wheat plant, as we have seen, are composed of the same elements as those which enter into the composition of mineral matter, though united into compounds which do not exist in the mineral world. Why then do we distinguish this matter when it takes the shape of a wheat plant, or a fowl, as living matter?

6r. The Living Plant increases in Size, by adding to the Substances which compose its Body, like Substances ; these, however, are not derived from without, but are manufactured within the Body of the Plant from simpler Materials.

In the spring, a wheat-field is covered with small 
green plants. These grow taller and taller until they attain many times the size which they had when they first appeared ; and they produce the heads of flowers which eventually change into ears of corn.

In so far as this is a process of growth, accompanied by the assumption of a definite form, it might be compared with the growth of a crystal of salt in brine: but, on closer examination, it turns out to be something very different. For the crystal of salt grows by taking to itself the salt contained in the brine, which is added to its exterior; whereas the plant grows by addition to its interior: and there is not a trace of the characteristic compounds of the plant's body, albumin, gluten, starch, or cellulose, or fat, in the soil, or in the water, or in the air.

Yet the plant creates nothing $\left(\S 5^{\circ}\right)$ and, therefore, the matter of the proteids and amyloids and fats which it contains must be supplied to it, and simply manufactured, or combined in new fashions, in the body of the plant.

It is easy to see, in a general way, what the raw materials are which the plant works up, for the plant gets nothing but the materials supplied to it by the atmosphere and by the soil. The atmosphere contains oxygen and nitrogen, a little carbonic acid gas, a minute quantity of ammoniacal salts, and a variable proportion of water. The soil contains clay and sand (silica), lime, iron, potash, phosphorus, sulphur, ammoniacal salts, and other matters which are of no importance. Thus, between them, the soil and the atmosphere contain all the elementary bodies which we find in the plant: but the plant has to separate them and join them together afresh. 
Moreover the new matter, by the addition of which the plant grows, is not applied to its outer surface, but is manufactured in its interior; and the new molecules are diffused among the old ones.

62. The Living Plant, after it has grown up, detaches part of its Substance, which has the Power of developing into a similar Plant, as a Seed.

The grain of wheat is a part of the flower of the wheat plant, which, when it becomes ripe, is easily separated. It contains a minute and rudimentary plant; and, when it is sown, this gradually grows, or becomes developed into, the perfect plant, with its stem, roots, leaves and flowers, which again give rise to similar seeds. No mineral body runs through a regular series of changes of form and size and then gives off parts of its substance which take the same course. Mineral bodies present no such development and give off no seeds or germs. They do not reproduce their kind.

63. The Living Animal increases in Size by adding to the Substances which compose its Body, like Substances; these however are chiefly derived directly from other Animals or from Plants.

The fowl in the farmyard is incessantly pecking about and swallowing now a grain of corn, and now a fly or a worm. In fact, it is feeding, and, as every one knows, would soon die if not supplied with food. It is also a matter of every day knowledge that it would not be of much use to give a fowl the soil of a corn-field, with plenty of air and water, to eat. 
In this respect, the fowl is like all other animals; it cannot manufacture the proteid materials of its body, but it has to take them ready made, or in a condition which requires but very slight modification. by devouring the bodies either of other animals or of plants. The animal or vegetable substances devoured are taken into the animal's stomach; they are there digested or dissolved; and thus they are fitted to be distributed to all parts of the fowl's own body, and applied to its maintenance and growth.

64. The Living Animal, after it has grown up, detaches part of its Substance, which has the Power of growing into a similar Animal, as an Egg.

The fowl's egg is formed in the body of the hen, and is, in fact, part of her body inclosed in a shell and detached. It contains a minute rudiment of a fowl; and when it is kept at a proper temperature by the hen's sitting upon it, or otherwise, for three weeks, this rudiment grows, or develops, at the expense of the materials contained in the yolk and the white, into a small bird, the chick, which is then hatched and grows into a fowl. The animal, therefore, is produced by the development of a germ in the same way as the plant; and, in this respect, all plants and all animals agree with one another and differ from all mineral matter.

65. Living Bodies differ from Mineral Bodies in their Essential Composition, in the manner of their Growth, and in the fact that they are reproduced by Germs.

Thus there is a very broad distinction between 
mineral matter and living matter. The elements of living matter are identical with those of mineral bodies; and the fundamental laws of matter and motion apply as much to living matter as to mineral matter ; but every living body is, as it were, a complicated piece of mechanism which "goes," or lives, only under certain conditions. The germ contained in the fowl's egg requires nothing but a supply of warmth, within certain narrow limits of temperature, to build the molecules of the egg into the body of the chick. And the process of development of the egg, like that of the seed, is neither more nor less mysterious than that, in virtue of which, the molecules of water, when it is cooled down to the freezingpoint, build themselves up into regular crystals.

The further study of living bodies leads to the province of Biology, of which there are two great divisions-Botany, which deals with plants, and Zoology, which treats of animals.

Each of these divisions has its subdivisions-such as Morphology, which treats of the form, structure, and development of living beings, and Physiology, which explains their actions or functions, besides others.

\section{IMMATERIAL OBJECTS.}

\section{Mental Phenomena.}

Material objects are all either not living, that is to say, mineral bodies, or they are living bodies. Everything which occupies space, offers resistance, has weight, and transfers motion, belongs to one or 
other of these two great provinces of nature. The sciences of Astronomy, Mineralogy, Physics, and Chemistry deal with the former, while Biology, with its two divisions of Zoology and Botany, treats of the latter. But natural knowledge is not exhausted by this catalogue of its topics. In the very first paragraph of this Primer, in fact, we had occasion to draw a distinction between Things, or material objects, and Sensations; and a moment's reflection is sufficient to convince you that sensations are not material objects. A smell takes up no space and has no weight; and to speak of a pound or of a cubic foot of sound, or of brightness, is, on the face of the matter, an absurdity. Pleasure is said metaphorically to be fugitive, but you cannot imagine a pleasure as a thing in motion.

What we call our Emotions are in like manner devoid of all the characters of material bodies. Love and hatred, for example, cannot for a moment be conceived to have shape, or weight, or momentum. And when, in reasoning, we think, our Thoughts have the same lack of the qualities of material things.

Sensations, emotions, and thoughts, thus constitute a peculiar group of natural phenomena, which are termed mental.

67. The order of Mental Phenomena: Psychology.

A definite order obtains among mental phenomena, just as among material phenomena; and there is no more chance, nor any accident, nor uncaused event, in the one series than there is in the other. Moreover, there is a connection of cause and effect between 
certain material phenomena and certain mental phenomena. Thus, for example, certain sensations are always produced by the influence of particular material bodies on our organs of sense. The prick of a pin gives pain, feathers feel soft, chalk looks white, and so on. The study of mental phenomena, of the order in which they succeed one another, and of the relations of cause and effect which obtain between them and material phenomena, is the province of the science of Psychology.

All the phenomena of nature are either material or inmmaterial, physical or mental; and there is no science, except such as consists in the knowledge of one or other of these groups of natural objects, and of the relations which obtain between them.

THE END.

\section{ITBR'ARY}




\section{EDWARD PATERSON,}

76, LITTLE BRITAIN, ALDERSGATE STREET, LONDON, E.C.

ELECTRICAL ENGINEER AND MANUFACTURER OF PHYSICAL APPARATUS.

AGENT TO THE SCIENCE AND ART DEPARTMENT, SOUTH KENSINGTON.

Complete sets of Apparatus as recommended in Prof. Balfour Stewart's "Physics" Primer.

No. 1 Set $\$ 18$ carriage paid to any part of the United Kingdom.

No. 2 Set $£ 11$ ditto.

Set of Chemical Apparatus, as recommended in Professor Roscoe's "Chemistry" Primer, 25 5s.

(The charge for packing will be 5 per cent. on the value of the set.)

All the above can be seen at our Show Rooms and Steam Works at 75 , Little Britain.

Apparatus for hire for illustration of Scientific Lectures.

Physical Apparatus of all descriptions for Science Teaching.

Paterson's Catalogues. Part I. Electrical Apparatus Post free $6 d$.

Paterson's Catalogues. Part II. Electric Signals. Post free $6 d$.

Paterson's Catalogues. Part III. Loan Apparatus and Scientific Lantern Slides. Post free $2 d$.

Libexal Terms to Shippers and Wholesale Buyers.

The above sets can also be ordered through Messrs. Macmillan \& Co. 


\section{MACMILLAN'S}

\section{SCIENCE PRIMERS.}

UNDER THE JOINT EDITORSHIP OF

PROFESSORS HUXLEY, ROSCOE, AND

BALFOUR STEWART.

Introductory. By Professor HUXLey, F.R.S. I8mo. Is.

Chemistry. By H. E. Roscoe, F.R.S., Professor of Chemistry in Owen's College, Manchester. $18 \mathrm{mo}$. Illustrated. xs. Wiih Questions.

Physics. By Balforr Stewart, F.R.S., Professor of Natural Philosophy in ()wen's College, Manchester. I8mo: Illustrated. Is. With Questions.

Physical Geography. By A. Getkiz, F.R.S.. Murchisen Professor of $\mathrm{Ge}, \log y$ and Mineralogy at Edinburgh. $18 \mathrm{mo}$. Illustrated. $x$. Wiih Questions.

Geology. By Professor GeIkIr, F.R.S. $18 \mathrm{mo}$. With numerous Illustrations. is.

Physiology. By Michael Foster, M.D., F.R.S. $18 \mathrm{mo}$. With numerous Illustrations. xs.

Astronomy. By J. Norman Lockyer, F.R.S. 18mo. With numerous Illustrations. $\mathbf{r s .}$

Botany. By Sir J. D. НооквR, K.C.S.I., C.B., President of the Royal Society. $18 \mathrm{mo}$. Illustrated. Is.

Ilogic. By Professor Stanlzy Jevons, F.R.S. I8mo. xs.

Political Economy. By Prufessur Jevons, F.R.S. 18mo. Is.

* Others to follow. 


\section{MACMILLAN'S}

\section{HISTORY AND LITERATURE PRIMERS.}

\section{Edited by JOHN RICHARD GREEN.}

Homer. By the Right Hon. W. E. Gladstone, M.P. 18 mo $x$. English Grammar. By the Rev. R. MORRIS, LL.D. I8mo. Is. Rome. By the Rev. M. CReigrton, M.A. r8mo. With Ir Maps. rs. Greece. By C. A. Fyprz, M.A. 18mo. With 5 Maps. Is.

English Literature. By the Rev. Stopford Brooke, M.A. r8ino. Is.

Europe. By E. A. Freeman, D.C.L., LL.D., M.A. r8mo. With Maps. Is.-

Greek Antiquities. By J. P. MaнaffY, M.A. $18 \mathrm{mo.}$ Illustrated. Is.

Roman Antiquities. By Prof. A. S. WrLkins. r8mo. Illustrated. Is.

Classical Geography. By H. F. Tozer, M.A. r8mo. Is.

Geography. By Grorge Grove, F.R.G.S. With Maps. I8mo is.

Children's Treasury of Iyrical Poetry. By F. T. PALGRAve. In Two Parts, each is.

Shakspere. By Prof. Downen. I8mo. Is.

Philologg. By J. Perle, M.A. r8mo. is.

Greek Literature. By Prof. R. C. ЈЕвв, M.A. $18 \mathrm{mo.} \mathrm{Is.}$

English Grammar Exercises. By R. Mokris, LL.D., and H. C. BoweN, M.A. I8mo. Is.

English Composition. By Prof. Nrchoz, $x 8 \mathrm{~m}$, Is.

France. By Charlotte M. Yonge. 18mo. is.

* * Others to follow.

Primer of Planoforte Playing. By Franklin TAYLor. Edited by George Grove, D.C.L. I8mo. is. 


\section{THE LIBRARY UNIVERSITY OF CALIFORNIA \\ Santa Barbara \\ Goleta, California}

\section{THIS BOOK IS DUE ON THE LAST DA STAMPED BELOW.}

\section{AVAILAB: T: TOT:}

CIRCULATIC: $:$

DISPLAFRIDE: EDD

APR 2860

NOH 281966 
UC SOUTHERN REGIONAL LIBRARY FACILITY

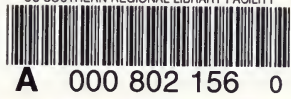




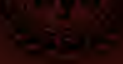

